\title{
Wheat (Triticum aestivum L.) selenium-binding protein-A enhances cadmium tolerance via interaction between CXXC motif and cadmium and detoxification
}

\author{
Fei Luo ${ }^{1}$, Dong Zhu ${ }^{1}$, Rong Zou ${ }^{1}$, Wenjing Duan ${ }^{1}$, and Yueming Yan ${ }^{1}$ \\ ${ }^{1}$ Capital Normal University
}

September 11, 2020

\begin{abstract}
Cadmium (Cd), one of the heavy metal pollution sources, has a strong impact on crop growth and development, yield formation, and food safety. In this work, we perform the first comprehensive study on the molecular mechanisms of wheat (Triticum aestivum L.) selenium-binding protein-A (TaSBP-A) that is involved in Cd-tolerance. As a cytoplasm protein, TaSBP-A was highly conservative in plants, but showed a high expression in plant roots; moreover, both transcription and translation expression levels were highly induced by Cd stress. TaSBP-A overexpression in yeast, Arabidopsis and wheat protoplasts enhanced Cd-tolerance via free $\mathrm{Cd}^{2+}$ accumulation and detoxification. In vitro $\mathrm{Cd}^{2+}$ binding assay combined with a thermodynamics survey by isothermal titration calorimetry as well as secondary structure analysis by circular dichroism showed that the CXXC motif in TaSBP-A was a major Cd-binding site that played important roles in the detoxification under Cd stress via its interaction with free $\mathrm{Cd}^{2+}$. Our results provide new insights into the molecular mechanism of plant Cd-tolerance as well as into the candidate gene for improving crop heavy metal resistance.
\end{abstract}

\section{1-INTRODUCTION}

Wheat (Triticum aestivum L.) serves as one of the most important grain crops that is broadly cultivated in the world. It has a high ability to adapt to various environments and provides a stable source of saccharides and proteins. Thus, it is highly important that human beings maintain wheat production and grain safety. However, agricultural soils have increasingly become contaminated with heavy metals, and this is a serious threat to grain production worldwide (Rizwan et al., 2012). In China alone, about one-fifth of agricultural land (nearly 20 million hectares) has been contaminated by heavy metal such as cadmium (Cd), mercury $(\mathrm{Hg})$ and lead $(\mathrm{Pb})$; in turn, this has resulted in a reduction of 250 million tons of yield and 50 tons of contaminated grains (Huamain et al., 1999). Cd is highly toxic to both plants and animals, even at very low concentrations (López-Luna et al., 2015). Predominantly, humans and animals come into contact with Cd-polluted foods via the food chain (Dai et al., 2012). People exposed to elevated environmental levels of $\mathrm{Cd}$ have a high risk of acquiring many diseases, including chronic kidney disease, osteoporosis, cardiovascular diseases, and cancer (Fatima et al., 2019).

$\mathrm{Cd}$ stress has done heavy damage to plant metabolic and physiological processes, inhibiting plant growth and development. Moreover, it can induce water stress, causing symptoms such as decreases in stomatal conductance, transpiration rate, and leaf relative-water content (Arasimowicz-Jelonek et al., 2011). Cdinduced signal transduction triggers reactive oxygen species (ROS) production, which impairs the membrane, cellular organelles and biomolecules (Ranieri et al., 2005). In wheat, Cd toxicity can cause physiological disorders such as a decrease in photosynthesis, sugars, soluble proteins, and antioxidant enzyme activities; 
in turn, this can lead to a severe inhibition of morphology and a reduction of biomass and grain yield (Li et al., 2015).

Plants have evolved various resistance mechanisms to mitigate cadmium stress, including restricting metal uptake and enhancing their detoxification abilities (Choppala et al., 2014). Given that plants encounter metals in the soil solution first via their root cell walls, the walls act as the first barrier against Cd (Lang \& Wernitznig, 2011). It is known that in bush beans, Cd ions are mostly bound to pectic sites and histidyl groups in the root and leaf cell walls (Leita et al., 1996). In addition, some plants release organic compounds into the rhizosphere to form complexes with Cd (Sarwar et al., 2010). Once Cd gets into the cytosol, plants can moderate $\mathrm{Cd}$ stress by forming metal chelates/complexes to minimize the concentration of free $\mathrm{Cd}$ in the cytosol (Saraswat \& Rai, 2011). To date, two principal peptides have been determined to play crucial roles in chelating to Cd: phytochelatins and metallothioneins (Ismael et al., 2019). These thiol moieties of phytochelatins and cysteine-rich small polypeptides enzymatically synthesized from glutathione are able to chelate metal ions such as $\mathrm{Cd}, \mathrm{Cu}, \mathrm{Zn}$ and $\mathrm{Ag}$. Similarly, metallothioneins that are tolerant to $\mathrm{Cu}$ and $\mathrm{Cd}$ are cysteine-rich proteins with a low molecular mass (Zhou \& Goldsbrough, 1994). Some transporters are involved in transporting metal complex into roots, vacuoles or xylem; these include Cd1 (Yan et al., 2019), HMA3 (Lei et al., 2020; Zhang et al., 2020) and YSL proteins (Curie et al., 2009).

The transcriptional regulation of $\mathrm{Cd}$ tolerance-related genes is a conserved strategy for plant response to heavy metal. Several Cd-responsive transcription factors in plants have been characterized, such as Arabidopsis FIT (Wu et al., 2012) and PvERF15 (Lin et al., 2017). In fact, these Cd-responsive transcription factors belong to the key downstream effectors of Cd stress transcriptional pathways that trigger the expression of Cd-detoxification genes and, thus, they converge Cd stress signals (Chmielowska-Bąk et al., 2014). In addition, many soluble metal receptor proteins, known as metallochaperones, can traffic metal ions in cytosol. ATX1 can bind a single $\mathrm{Cu}$ ion by two cysteines in the MXCXXC motif ( $\mathrm{M}$ is methionine, $\mathrm{X}$ is any amino acid, and C is cysteine) (Lin \& Culotta, 1995). This motif is also present in numerous metal binding proteins, such as the P-type copper transporter CCC2 (Yuan et al., 1995), bacterial carriers for mercury ions MerP (Powlowski \& Sahlman, 1999), copper chaperones for SOD1 CCS (Culotta et al., 1997), and the cadmium binding protein Cd19 (Suzuki et al., 2002).

The selenium-binding protein (SBP), a typical SBP56 family member, is well characterized in A. thaliana (Dutilleul et al., 2008; Hugouvieux et al., 2009; Schild et al., 2014). It was firstly identified as a cytosolic selenium binding protein (SBP, originally termed as SBP56) in mouse liver that showed that it could bind radioactive selenium (Bansal et al., 1989, 1990). SBP serves as an intra-Golgi protein transport in Mammalia (Porat et al., 2000). The decreased levels of SBP1 are associated with various cancers, such as epithelial cancers and breast cancer (Yang et al., 2013). In plants, SBP was first found in Lotus japonicas, which was associated with nodule formation, and it functioned during the symbiosis of plants and rhizobia (Flemetakis et al., 2002). The overexpression of rice to $S B P 1$ enhanced its tolerance to different pathogens (Sawada et al., 2004). In particular, overexpressing AtSBP1 conferred tolerance to Cd stress in Arabidopsis suspension cells (Sarry et al., 2006) and entire plants (Dutilleul et al., 2008). AtSBP1 also responds to other stresses such as $\mathrm{Zn}, \mathrm{Cu}$ and $\mathrm{H}_{2} \mathrm{O}_{2}$; in addition, it participates in the sulfur and glutathione requirements in cells (Hugouvieux et al., 2009). The Se-binding site $\mathrm{Cys}^{21} \mathrm{Cys}^{22}$ of AtSBP1 was identified, which could form SeCys [R-S-Se(II)-S-R] and could confer Se tolerance (Agalou et al., 2005; Schild et al., 2014). Although the binding ability of AtSBP1 to Cd was verified by an in vitro assay (Dutilleul et al., 2008), the specific binding site of SBP to heavy metal in plants is still unknown. Furthermore, the overexpression of AtSBP1 could result in greater accumulation of $\mathrm{Cd}$ in Arabidopsis (Dutilleul et al., 2008), indicating that AtSBP1 could enhance the $\mathrm{Cd}$ uptake. However, the state (free or complex) of the accumulated $\mathrm{Cd}$ in the overexpressed plants remains unclear; this is critical as it will allow researchers to further dissecting the mechanisms of SBP for Cd tolerance.

In the current study, a comprehensive investigation was performed to reveal the molecular mechanisms of wheat TaSBP-A enhancing Cd tolerance. We focused on dissecting the detoxification function of TaSBP-A via a specific Cd-binding motif. Our results provide new insights into the Cd-tolerant mechanisms of plants, 
which could be beneficial for improving the Cd tolerance of crop cultivars.

\section{2 | MATERIALS AND METHODS}

\subsection{Wheat materials, seedling cultivation and Cd treatment}

The seeds of wheat variety Chinese Spring (CS) were cultivated according to Zhang et al. (2014). When seedlings reached to three-leaf stage, the salt stress treatment was performed with $50 \mu \mathrm{M} \mathrm{CdCl}_{2}$. Both treatment and control included three biological replicates. The samples of roots, stems and leaves were respectively collected from $24,48,72 \mathrm{~h}$ treatments and control, and then immediately immerged into liquid nitrogen prior to use.

\section{2 | RNA-seq and RT-qPCR}

The expression profiling of TaSBP genes in different organs was detected using the RNA-seq database of wheat (http://www.wheat-expression.com/genes/heatmap? gene_set=RefSeq1.18genes=TraesCS3A02G422100\%2CTraesCS3D02G417500\%2CTraesCS3B02G457600).

Total RNA isolation, cDNA synthesis and real-time quantitative polymerase chain reaction (RT-qPCR) were based on the previous report (Yu et al., 2016). The expression levels of TaSBP were presented as values relative to the corresponding control samples at the indicated times and conditions after normalization to Ubqutin (UBI) transcript levels. The primers were shown in Table S1.

\section{3 | Subcellular localization}

The full-length coding sequence of TaSBP without a stop codon was cloned and ligated into 16318hGFP vector driven by the cauliflower mosaic virus $35 \mathrm{~S}$ promoter. Subsequently, the reconstructive plasmid DNA and 16318hGFP control were respectively transformed into leaf protoplasts of Chinese Spring by PEG4000 based on Zou et al. (2020). After incubation at $23^{\circ} \mathrm{C}$ in darkness condition overnight, the GFP signal and chlorophyll red auto-fluorescence were monitored and photographed using confocal laser scanning microscope (Leica TCS SP5, Germany).

\section{$2.4 \mid$ Overexpression of $T a S B P-A$ in Saccharomyces cerevisiae}

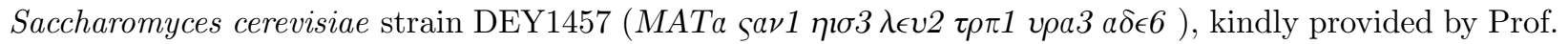
Liping Yin, Capital Normal University, was used for heterologous expression of TaSBP-A protein. The full gene CDS of TaSBP-A was cloned in the destination vector PYES2 (Invitrogen). The empty vectors $(\mathrm{EV})$ and combined vectors were respectively transformed into yeast strains DEY1457 following standard procedure (Invitrogen). Single colonies cultured in the exponential phase (OD 2.0) were diluted to six stepped concentration and drop on the dextrose-Ura solid medium with/without $30 \mu \mathrm{M} \mathrm{Cd}$. Experiments were always conducted using three independent clones.

\section{5 | Overexpression of $T a S B P-A$ in Arabidopsis and Cd stress treatment}

Transgenic Arabidopsis lines were generated and cultivated according to Li et al. (2017). The expression vector was pCAMBIA1302, whose GFP-tag was replaced by Flg-tag. Transgenic lines were obtained and at least two generations of resistance screening were performed. Seeding plants were grown vertically to allow root and shoot collection. After 7 days, seedlings were transferred to $1 / 2$ MS medium with 0,75 , $150 \mu \mathrm{M} \mathrm{CdCl}_{2}$ for another 7 days. As an indicator of Cd sensitivity, seedling root length, fresh weight and survive rate were measured. Meanwhile, Arabidopsis plants were grown in garden soil (Basic substrate No. 1, Pindstrup Mosebrug A/S, Denmark) without additional fertilizer for Cd stress treatment. Young plants 
were cultivated for three weeks and then used for Cd treatment by watering with and without $150 \mu \mathrm{M} \mathrm{CdCl}_{2}$ solution, respectively.

2.6 Measurements of chlorophyll, malondialdehyde and $\mathrm{H}_{2} \mathrm{O}_{2}$ content, SOD activity and chlorophyll fluorescence

Wild-type and transgenic Arabidopsis plants were treated with $150 \mu \mathrm{M}$ Cd for 4 weeks. Chlorophyll and malondialdehyde (MDA) content and superoxide dismutase (SOD) activity were measured as previous report (Li et al., 2017). $\mathrm{H}_{2} \mathrm{O}_{2}$ was measured using kit (KGT018, KeyGen Biotech, China) according to the manufacturer's instructions. IMAGING-PAM chlorophyll fluorometer (Walz, Effeltrich, Germany) was used for measuring chlorophyll fluorescence (Schreiber et al., 2007). The wild-type and transgenic plants were exposed to 20 photons $\mathrm{m}^{-2 *} \mathrm{~s}^{-1}$ (actinic light) after dark-adaptation and maximal PSII quantum yield (Fv/Fm) was detected. The irradiance of the measuring light used for the F0 measurement was $2 \mu \mathrm{M}$ photons $\mathrm{m}^{-2} \mathrm{~s}^{-1}$, and that of the supersaturating light for Fm and Fm' measurements were $5000 \mu \mathrm{M}$ photons $\mathrm{m}_{-}{ }^{2}{ }^{-1}{ }^{-1}$. The equation was used to calculate $\mathrm{Fv} / \mathrm{Fm}: \mathrm{Fv} / \mathrm{Fm}=(\mathrm{Fm}-\mathrm{F} 0) / \mathrm{Fm}$. The effective PS II quantum yield ( PPSII) was calculated according to the formula: $\Phi$ PSII $=\left(F m^{\prime}-F\right) / F m^{\prime}$. The inhibition of PSII quantum yield (Inh) was calculated based on the equation: Inh $=(\Phi P S I I$ control- $\Phi$ PSII sample $) / \Phi P S I I$ control.

\section{7 | Measurement of total Cd content in yeast cells and plant extracts}

Cd-treated and untreated yeast cells and plant leaves were dried for $3 \mathrm{~d}$ at 55 , and then put into digestion tank. Pre-digesting was conducted by adding $5 \mathrm{~mL} \mathrm{65 \%} \mathrm{HNO}_{3}$ (Suprapur; Merck) and $2 \mathrm{~mL} \mathrm{H}_{2} \mathrm{O}_{2}$ (Suprapur; Merck) to the digestion tank for $40 \mathrm{~min}$ at room temperature. The samples were digested by microwave digestion instrument (MARS, CEM Corporation, USA) for $2 \mathrm{~h}$. Cd content ( $\mu \mathrm{g} / \mathrm{g}$ DW) in the extracts was determined by using inductively couple mass spectrometry (ICP-MS, ELAN DRC-e, PerkinElmer) based on Maher et al. (2001).

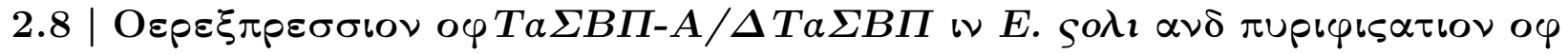 $\tau \eta \varepsilon \rho \varepsilon \varsigma O \mu \beta เ \nu \alpha \nu \tau \pi \rho \circ \tau \varepsilon เ \nu \varsigma$}

The mutant $(\triangle$ TaSBP-A) containing displaced Cys with Gly in putative metal binding regions was constructed. The primers were shown in Table S1. cDNA contained in the entry clone was cloned into the destination vectors pEGX-4T-1, used to produce GST-TaSBP-A/ $\Delta$ TaSBP protein carrying additional 250 amino acids at the $\mathrm{N}$ terminus compared to the recombinant proteins. The recombinant plasmids were transformed into E. colistrain BL21. The cell cultures were fostered at 37 for $3-4 \mathrm{~h}$ until the OD $=0.6-0.8$, and then $1 \mathrm{mM}$ IPTG was added for induction $16 \mathrm{~h}$ at 16 . The recombinant proteins were isolated by batch purification with glutathione sepharose 4B based on the manufacturer's instructions (Amersham). Protein concentrations were determined by spectrophotometer (NanoDrop 2000, Thermoscientific) at $280 \mathrm{~nm}$.

\section{9 | In vitro $\mathrm{Cd}^{2+}$ binding shift and binding ratio measurement}

Two constructs were prepared: a wild type with the normal CXXC motif (TaSBP-A), and a mutant with the GXXG motif ( $\Delta$ TaSBP-A). The recombinant protein $(100 \mu \mathrm{M})$ of TaSBP-A/DTaSBP was incubated with $500 \mu \mathrm{M} \mathrm{CdCl}_{2}$ and $500 \mu \mathrm{M} \mathrm{CdCl}_{2}$ together with $500 \mu \mathrm{M}$ EDTA at 4 overnight. The shift was detected with $10 \%$ SDS-PAGE. The recombinant plasmid of pEGX-Ta $\Sigma B \Pi-A / \Delta T a \Sigma B \Pi$ was transformed intoE. coli BL21 (DE3) and induced at 16 for $10 \mathrm{~h}$ with $1 \mathrm{mM}$ IPTG. Then, $100 \mu \mathrm{M} \mathrm{CdCl} 2$ was added to the liquid medium for $10 \mathrm{~h}$ culture. The cells were collected and mildly lysed using BugBuster Master Mix (Novagen, 71456-4). The lysis was centrifuged at $16000 \mathrm{~g}$ and 4 for $15 \mathrm{~min}$. The purified proteins were divided into equal two parts: one used for measuring Cd content by ICP-MS, and the other for measuring the protein concentration by DC protein determination kit (Bio-Rad). The stoichiometry of protein binding to Cd was performed based on Cd and protein concentration based on Luo et al. (2019). 
2.10 Thermodynamic parameters determined by isothermal titration calorimetry (ITC) and secondary structure characterization by circular dichroism (CD)

Cd-TaSBP-A/ $\triangle$ TaSBP thermodynamic parameters were detected by calorimetric experiments of the recombinant TaSBP-A/ $\Delta$ TaSBP proteins. $\mathrm{Cd}^{2+}(500 \mu \mathrm{M})$ was added by successive injections $(1 \mu \mathrm{L})$ to TaSBP$\mathrm{A} / \Delta \operatorname{TaSBP}(50 \mu \mathrm{M})$ in a total volume of $0.22 \mathrm{~mL}$. Buffer conditions were $10 \mathrm{mM}$ HEPES, $\mathrm{pH} 7.4$ and $150 \mathrm{mM} \mathrm{NaCl}$. Calorimetric titrations were performed at $25^{\circ} \mathrm{C}$ with stirring at $1000 \mathrm{rpm}$ with a filter time constant of $2 \mathrm{~s}$ using a microcalorimeter (Microcal ITC 200 System, GE Healthcare). Negative controls were performed by the injections into the buffer, resulting only in signals from heat of salt dilution. Data were analyzed with Origin ITC 200 software.

Secondary structure characterization (modifications) of the recombinant TaSBP-A protein after incubation with $\mathrm{Cd}^{2+}$ was performed by circular dichroism (CD). The recombinant protein of TaSBP-A/ $\Delta$ TaSBP $(1$ nmol) was incubated with gradient concentration of $\mathrm{Cd}^{2+}(0,2,3,4 \mathrm{nmol})$ in a total volume of $250 \mu \mathrm{L}$ incubation buffer containing $10 \mathrm{mM}$ HEPES (pH 7.4) and $150 \mathrm{mM} \mathrm{NaCl}$. Spectra acquisition was performed at $25^{\circ} \mathrm{C}$ using a spectropolarimeter (J-815, Jasco) in the far UV (200-260 nm) with the following parameters: $1 \mathrm{~nm}$ step, $2 \mathrm{~nm}$ band width, and scan speed $200 \mathrm{~nm} / \mathrm{min}$ with the optical path length $1 \mathrm{~mm}$. The assessment of protein second structure was carried out by K2D method based on the linear regression method of Yang algorithm (Yang et al., 1986).

\subsection{Measurement of $\mathrm{Cd}^{2+}$ fluxes and Cd microscopic imaging}

One-week-old Arabidopsis seedlings cultivated on 1/2 MS were used to measure $\mathrm{Cd}^{2+}$ fluxes. Net fluxes of $\mathrm{Cd}^{2+}$ in root hair were measured by the noninvasive micro-test technique (NMT; BIO-001A, Younger United States Science and Technology Corp, Beijing, China) combined with IFLUXES/IMFLUXES 2.0 software (NMT100 Series, Younger USA, Amherst, MA, USA) (Ma et al., 2015). In brief, the microelectrodes were calibrated in 0.1 and $0.01 \mathrm{mM} \mathrm{Cd}^{2+}$ before the measurements of $\mathrm{Cd}^{2+}$ flux. Only electrodes with Nernstian slopes $>29 \pm 3 \mathrm{mv} /$ decade were used. Arabidopsis seedlings were transferred into a measuring chamber containing $10 \mathrm{~mL}$ of measuring solution $\left(0.1 \mathrm{mM} \mathrm{KCl}, 0.03 \mathrm{mM} \mathrm{CdCl}_{2}\right.$, and $0.3 \mathrm{mM} \mathrm{MES,} \mathrm{pH} \mathrm{5.8.)} \mathrm{and}$ equilibrated for $10 \mathrm{~min}$ before measurement.

Visualization of free $\mathrm{Cd}^{2+}$ in Arabidopsis roots was performed in 1-week-old seedlings. The Cd probe Leadmium $^{\mathrm{TM}}$ Green AM dye (Molecular Probes, Invitrogen, Calsbad, CA, USA) was utilized to detect the distribution of $\mathrm{Cd}$ in plant roots pre-treated with $150 \mu \mathrm{M} \mathrm{Cd}^{2+}$ for 0,6 and $12 \mathrm{~h}$. A stock solution of Leadmium $^{\mathrm{TM}}$ Green AM dye was made with adding $50 \mu \mathrm{L}$ of DMSO to the origin one vial dye. Then, the stock was diluted with 1:100 of $0.85 \% \mathrm{NaCl}$. Roots were immersed in the solution for $90 \mathrm{~min}$ in the dark. Cd fluorescence was excited at $488 \mathrm{~nm}$ and visualized by using Zeiss LSM 780 (Carl Zeiss, Germany). All images were taken at 200 magnification.

\subsection{Overexpression of $T a S B P-A$ in wheat protoplasts and function verification}

The leaf protoplasts of Chinese Spring were extracted and transformed according to Zou et al. (2020). The protoplasts were cultivated overnight after transformation of plasmids including $16318 \mathrm{hGFP}$, reconstructive $T a S B P-A$ and $\triangle T a \Sigma B \Pi-A$, respectively. Then, the cells were treated with $50 \mu \mathrm{M} \mathrm{CdCl}_{2}$ for $0,2,4,6$, 8,10 , and $12 \mathrm{~h}$. To determine cell viability, the fluorescence of GFP and chloroplast autofluorescence were observed by confocal laser scanning microscope (Leica TCS SP5, Germany). The transgenic protoplasts were cultivated in $0 \mu \mathrm{M} \mathrm{Cd}$ as the control (CK). The relative rate of protoplasts viability (treatment group/CK) was counted from 0 to $12 \mathrm{~h}$. 


\section{3 | RESULTS}

\subsection{Phylogenetics and structural characterization of TaSBPs}

Three protein sequences (TraesCS3A01G422100.1, TraesCS3B01G457600.1 and TraesCS3D01G417500.1) the in Chinese Spring Protein database (http://plants.ensembl.org/index.html) were highly homologous to Arabidopsis SBPs (AtSBP1/2/3); in turn, they respectively located on chromosomes 3A, 3B and 3D. Specifically, TraesCS3A01G422100.1 showed $98.59 \%$ and $97.37 \%$ identities to TraesCS3B01G457600.1 and TraesCS3D01G417500.1, respectively (Figure S1). This indicates that only three SBP copies are present in hexaploid wheat, and they are named TaSBP-A, TaSBP-B and TaSBP-D. A phylogenetic tree constructed by 11 SBPs from different animal and plant species showed that all SBPs were highly conservative and that TaSBP-A/B/D had quite a close phylogenetic relationship with the SBP56 family (Figure 1a).

Structural characterization showed that TaSBPs belonged to the SBP56 family and contained a putative heavy metal binding motif as well as a selenium-binding site CC (Figure 1b). They also showed a partial similarity with other typical metal binding proteins in the metal binding region CXXC (Figure 1c). To identify the potential Cys residues involved in Cd binding, a three-dimensional model analysis of TaSBP-A was performed using SWISS-MODEL (https://swissmodel.expasy.org/). The structure of the hypothetical selenium-binding protein fromSulfolobus tokodaii (SMTL ID: 2ece.1) was the closest homologue and, as such, it was used to generate a three-dimensional model with the program Modeler (Global Model Quality Estimation of $0.7 ; 43.91 \%$ sequence identity). As shown in Figure 1d, nine potential Cys residues were located on the surface of the TaSBP-A protein, while four Cys residues showed $100 \%$ conservation $\left(\mathrm{Cys}^{100}\right.$, $\mathrm{Cys}^{102}$, $\mathrm{Cys}^{161}$, and $\mathrm{Cys}^{488}$, as shown in Figure S1). $\mathrm{Cys}^{23}$ and $\mathrm{Cys}^{24}$ were conserved in all the photosynthetic organisms; in turn, they were identified as the selenium-binding sites in Arabidopsis (Schild et al., 2014). The $\mathrm{Cys}^{100}$ and $\mathrm{Cys}^{102}$ on the random coil belonged to a CXXC motif putatively involved in metal and Cd binding (Lin \& Culotta, 1995; Suzuki et al., 2002; Yuan et al., 1995).

\subsection{Expression and subcellular localization of TaSBP-A}

RNA-seq analysis of the three TaSBPs in different organs of wheat showed that all TaSBPs expressed in root, stem and leaf. Of these, TaSBP-A had the highest expression level in three organs, particularly in the plant root (Figure 2a). Further, an RT-qPCR analysis showed a similar expression pattern in different organs (Figure $2 \mathrm{~b}$ ). According to these results, we selected TaSBP-A for further functional research, as it has a 1485 bp encoding, 495 amino acid residues, and a $M \mathrm{r} 54.1 \mathrm{kDa}$.

To determine the subcellular location of the TaSBP-A, a TaSBP-A -GFP fusion vector (pTaSBP-A-GFP) driven by two CaMV35S promoter was constructed and transformed into wheat protoplasts. As a negative control, transgenic protoplasts expressing only GFP were used. In cells expressing only GFP, the entire cytoplasm and nucleus were diffusely labeled, as observed by a laser scanning microscopy. In contrast, the GFP fluorescence of TaSBP-A-GFP was only visible at cytoplasm, which clearly indicates that the TaSBP-A was localized in the cytoplasm (Figure 2c).

\subsection{Cd stress response of $\operatorname{TaSBP}-A$ in wheat and overexpressed yeast cells}

The TaSBP-A expression in response to Cd stress in the seedling roots of Chinese Spring was detected by both RT-qPCR (Figure 3a) and Western blot (Figure 3b). The results showed that both the transcription and translation expression of TaSBP-A were significantly induced by Cd stress. In particular, the transcription and translation levels of TaSBP-A dramatically increased by 1.43-3.81 times compared to the control; this suggests that it has potential roles in Cd stress response.

Because yeast has no SBP homolog, we overexpressed the TaSBP-A in yeast to detect the Cd tolerance of yeast cells. The cDNA of TaSBP-A was introduced into the yeast strain DEY1457 and EV was transferred into yeast DEY1457 as a negative control. Under normal growth conditions, both EV and TaSBP-Acells had 
a practically equal growth rates; however, the TaSBP-Acells showed a higher growth rate than did the $E V$ cells under $30 \mu \mathrm{M} \mathrm{Cd}^{2+}$ treatment for 3 days on the dextrose-Ura solid medium (Figure 3c). This indicates that $T a S B P-A$ could significantly enhance the Cd tolerance of yeast. Subsequently, we respectively cultured $E V$ and TaSBP-A cells in a liquid medium containing $25 \mu \mathrm{M} \mathrm{CdCl} 2$; here, the Cd content in yeast was determined by ICP-MS. Interestingly, the TaSBP-Aoverexpression in yeast could accumulate more $\mathrm{Cd}$ than EV significantly, as shown to be by $10.8 \%$ (Figure $3 \mathrm{~d}$ ). These results indicate that TaSBP-A can enhance the $\mathrm{Cd}$ tolerance of yeast cells by accumulating higher levels of $\mathrm{Cd}$.

\section{4 | Overexpressing TaSBP-Aenhanced Cd tolerance of Arabidopsis}

We overexpressed the TaSBP-A in Arabidopsis to further reveal its function in response to Cd stress. Three stable overexpressed transgenic lines (S2-9, S3-12 and S4-7) were obtained by using genome PCR and Western blot detection (Figure S2). The seedlings of the TaSBP-Atransgenic lines and WT were cultivated on $1 / 2$ MS containing 0,75 , and $150 \mu \mathrm{M} \mathrm{CdCl}_{2}$ for 7 days. The primary root growth was significantly inhibited and substantial chlorosis of cotyledons occurred in the WT plants (Figure S3a). However, TaSBP-A overexpressed seedlings maintained a higher fresh weight, root length and survival rate (Figure S3b-d), showing that they have a palpable $\mathrm{Cd}$ tolerance. The $\mathrm{Cd}$ accumulation measurement revealed that the overexpression of TaSBP$A$ lines could accumulate a greater amount of $\mathrm{Cd}$, specifically 1.13-1.23 times as high as WT (Figure 3e).

The Cd tolerance under $150 \mu \mathrm{M} \mathrm{CdCl}_{2}$ treatment of TaSBP-A overexpressed lines grown in garden soil was further detected. Under normal conditions, neither transgenic lines nor WT had clear differences in the growth. However, under Cd stress, the WT plants showed chlorosis leaves and a severe reduction of growth (Figure 4a). In contrast, the TaSBP-A transgenic plants displayed a clear resistance to Cd stress even though some chlorosis leaves still occurred. Physiological and biochemical parameter analyses showed that TaSBP-A overexpressed lines had higher SOD activity and lower $\mathrm{H}_{2} \mathrm{O}_{2}$ and MDA contents than did WT plants under $\mathrm{Cd}$ treatment (Figure $4 \mathrm{~b}-\mathrm{d}$ ). These results demonstrated that TaSBP-A transgenic plants could effectively promote SOD activity that would be able to alleviate the oxidative stress triggered by heavy-metal-induced $\mathrm{H}_{2} \mathrm{O}_{2}$. Cd accumulation in the roots of ICP-MS showed that the TaSBP-Atransgenic lines accumulated more Cd, 1.23-1.64 times higher than WT (Figure 4e); this is consistent with the results of $1 / 2 \mathrm{MS}$ cultivated seedlings (Figure S3e).

We also investigated the impairment of photosynthesis as a result of Cd stress in transgenic plants. The results showed that under normal conditions, the chlorophyll fluorescence parameters had no clear differences between WT and TaSBP-A overexpressed lines (Figure 4f). However, the maximum quantum yield of PSII photochemistry in the dark-adapted state $(\mathrm{Fv} / \mathrm{Fm})$ in the transgenic leaves under $150 \mu \mathrm{M}$ Cd was higher than it was for WT (Figure 4g). In particular, the operating efficiency of PSII (ФPSII) in three overexpression lines under Cd treatments was 22.25-28.80\%, which was significantly higher than it was for WT (Figure 4f, h). Cd exposure significantly increased the inhibition of PSII quantum yield (Inh) in the leaves of WT plants, but it had no clear effects on transgenic plants (Figure 4f, i). Similarly, the chlorophyll content in the leaves did not differ significantly between WT and the TaSBP-A transgenic lines after 4 weeks in normal growth conditions, while the TaSBP-A transgenic lines were significantly higher chlorophyll content under Cd stress: 1.95-2.95 times as high as WT (Figure 4j). These results indicate that the TaSBP-A overexpressed lines had no significant loss of photochemical efficiency under $150 \mu \mathrm{M}$ Cd stress when comparing them with WT plants.

\section{5 | Net fluxes and state of over-accumulated $\mathrm{Cd}^{2+}$ in transgenic Arabidopsis}

As described above, the overexpression of TaSBP-A resulted in increase of $\mathrm{Cd}$ accumulation, which has the ability to elevate the impairment of heavy metal $\mathrm{Cd}$ to plants. We detected the net fluxes of $\mathrm{Cd}^{2+}$ in the root hairs of transgenic Arabidopsis under $30 \mu \mathrm{M} \mathrm{Cd}^{2+}$ using a noninvasive micro-test technique (Figure $5 \mathrm{a})$. The results showed that the $\mathrm{Cd}^{2+}$ net fluxes in the root hairs of three transgenic lines $\mathrm{S} 2-9, \mathrm{~S} 3-12$, and S4-7 were $2.49,4.11$ and $3.20 \mathrm{pmol} \mathrm{cm}{ }^{-2} . \mathrm{s}^{-1}$ respectively, which is 1.8-2.9 times higher than WT (Figure $5 \mathrm{~b}$ ). 
This confirmed that a TaSBP-A overexpression could enhance the $\mathrm{Cd}^{2+}$ accumulation of plants.

We further used the $\mathrm{Cd}$ probe, Leadmium ${ }^{\mathrm{TM}}$ Green $\mathrm{AM}$ dye to detect the state (free or binding) of the accumulated $\mathrm{Cd}$, particularly with regard to the distribution of free $\mathrm{Cd}^{2+}$ in plant roots. This dye has a high affinity for $\mathrm{Cd}$, but it is insensitive to other divalent ions (except for lead). As such, it serves as a good candidate to identify free $\mathrm{Cd}^{2+}$ in plant cells ( $\mathrm{Lu}$ et al., 2008). As shown in Figure 5c, a very low level of green fluorescence was observed in the roots of transgenic lines. This indicates that this dye has a high specificity to detect $\mathrm{Cd}^{2+}$ and that it does not react with divalent ions such as the $\mathrm{Ca}^{2+}$ present in the control roots. In contrast, the green fluorescence signals in WT plants appeared clearly above the hypocotyl after a $6 \mathrm{~h}$ pretreatment of $150 \mu \mathrm{M} \mathrm{Cd}$; they were more obviously enhanced after a $12 \mathrm{~h}$ pretreatment of 150 $\mu \mathrm{M} \mathrm{Cd}$ in WT plants. However, the slight green fluorescence signals in the overexpression lines were only present below hypocotyl. These results indicated that overexpressed TaSBP-A played an important role in reducing free $\mathrm{Cd}^{2+}$ and that the over-accumulated $\mathrm{Cd}$ in the $T a S B P-A$ overexpression lines was present largely in binding state.

\section{6 | Determination of Cd-Binding Site in TaSBP-A}

The above results indicate that TaSBP-A can enhance Cd tolerance via Cd absorption and accumulation. Thus, it is crucial to determine the Cd binding site in TaSBP-A in order to dissect the molecular mechanism of plant Cd-tolerance. TaSBP-A and $\triangle$ TaSBP-A were expressed in E. coli as a fusion protein with GST (Figure S4a). Subcellular localization showed that the mutant of CXXC had no influence on the location of TaSBP-A (Figure S4b). Thus, we performed an in vitro $\mathrm{Cd}^{2+}$ binding assay based on the principle that ethylenediaminetetraacetic acid (EDTA) can chelate with $\mathrm{Cd}^{2+}$ to form Cd (II)-EDTA (Yang \& Davis, 1999). As shown in Figure 6a, both recombinant TaSBP-A and $\triangle$ TaSBP-A had shifts in SDS-PAGE after incubation with $500 \mu \mathrm{M} \mathrm{CdCl} 2$; in contrast, the shift disappeared with EDTA and the $\mathrm{Cd}$ coexistence in incubation buffer. However, after binding $\mathrm{Cd}^{2+}$, it was hard to recognize the shift between TaSBP-A and $\Delta$ TaSBP-A. ICP-MS combined with protein quantification was further used to identify the stoichiometry of the interaction between $\mathrm{Cd}$ and protein, and the results showed that the stoichiometry of the TaSBP-A: $\Delta$ TaSBP-A binding to $\mathrm{Cd}$ was about 3:2 (2.98:1.59) (Figure $6 \mathrm{~b}$ ). This indicates that the ability of TaSBP-A decreased by $47.3 \%$ after the CXXC motif mutation. This result further witnessed the interaction between TaSBP-A with Cd, where the CXXC motif served as the heavy metal binding site in the TaSBP-A.

3.7 Thermodynamic parameter analysis of the $\mathrm{Cd}^{2+}$ interactions with TaSBP-A and the impact of $\mathrm{Cd}^{2+}$ binding on TaSBP-A's Secondary Structure

The interaction of $\mathrm{Cd}^{2+}$ with TaSBP-A and $\Delta$ TaSBP-A was detected by an ITC that allows the determination, in one titration, of the stoichiometry, affinity, and enthalpic or entropic contributions to the Gibbs free energy. The ITC curves and thermodynamic parameters obtained during the interaction of $\mathrm{Cd}^{2+}$ and TaSBP-A/ $\Delta$ TaSBP-A are shown in Figure $6 \mathrm{c}$ and Table 1. For each $\mathrm{Cd}^{2+}$ injection, a release of heat was observed (Figure 6c, upper panel); this indicates that a clear binding event between $\mathrm{Cd}^{2+}$ and TaSBPA/ $\Delta$ TaSBP-A occurred. A one-site binding model was used to fit TaSBP-A/ $\Delta$ TaSBP-A isotherms (Figure $6 \mathrm{c}$, lower panel). This allowed us to determine an apparent binding affinity constant (K) in the low micromolar range $(50 \mu \mathrm{M})$. Unexpectedly, the binding enthalpy value of the $\mathrm{Cd}^{2+}$ and TaSBP-A interaction was -17.92 $\mathrm{kcal} / \mathrm{mol}$, which was significantly higher than that of the $\mathrm{Cd}^{2+}$ and $\Delta$ TaSBP-A interaction $(-13.30 \mathrm{kcal} / \mathrm{mol})$ (Table 1). Therefore, we deduced that the two different strong negative enthalpy values $(\Delta \mathrm{H})$ obtained for $\mathrm{Cd}^{2+}$ most likely correspond to a combination of a binding event with a specific covalent reaction between TaSBP-A/ $\Delta$ TaSBP-A and $\mathrm{Cd}^{2+}$. However, less heat was released in the interaction of $\Delta$ TaSBP-A with $\mathrm{Cd}$, which suggests that the Cd binding amount of TaSBP-A was palpably diminished after the mutation of the CXXC motif. The CXXC motif also witnessed entropy difference values $(\Delta S)$, a measurement for disorder and order in atomic and molecular assemblies (Landsberg, 1984). According to $\Delta \mathrm{S}_{\text {TaSBP-A }}<\Delta \mathrm{S}_{\Delta \mathrm{T} \alpha \Sigma \mathrm{B} \Pi-\mathrm{A}}$, TaSBP-A was able to bind more $\mathrm{Cd}^{2+}$ than $\Delta$ TaSBP-A was able to bind, leading to a dramatic decrease in $\Delta \mathrm{S}$. Furthermore, the fact that the calorimetric signals needed abnormally large amounts of time to recover to their baseline values after the CXXC motif mutation (Figure 6c) suggests that a covalent reaction coupled 
with the binding of the ion was significant restrained due to the CXXC motif mutation in TaSBP-A. Accord-

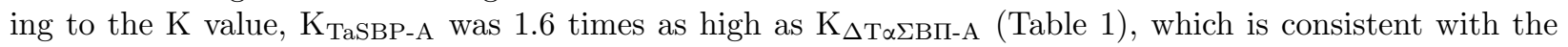
results of the stoichiometry TaSBP-A/DTaSBP-A (Figure 6b). This indicates that the ability of TaSBP-A to bind to Cd was heavily suppressed after the loss of CXXC motif, which can reduce the affinity of other binding sites in TaSBP-A to Cd

$\mathrm{CD}$ analysis was used to further determine whether Cd-binding resulted in changes of the protein's secondary structure. The CD spectrum recorded the far-UV with TaSBP-A, $\triangle$ TaSBP-A, Cd-bound TaSBP-A and Cdbound $\triangle$ TaSBP-A (Figure 6d) to estimate the second structure of proteins and Cd-proteins complexes. According to Table S2, the mutation of the CXXC motif had no effects on the $\beta$-sheet (about 45\%) and turn (about $7.4 \%$ ) content, but it led to an increase in random coil and a decrease in $\alpha$-helix. With the presence of $\mathrm{Cd}^{2+}$, the spectrum of TaSBP-A had more significant changes than did $\Delta$ TaSBP-A, indicating that the Cd-binding to TaSBP-A and the complex formation led to clear second structure alterations (Figure 6d). According to Table S2, the changes of TaSBP-A were obviously observed in the $\alpha$-helix, $\beta$-sheet, turn and random coil content after binding to $\mathrm{Cd}$; in contrast, $\triangle$ TaSBP-A had only changes in turn content. These results showed that the significant changes of TaSBP-A's second structure occurred upon $\mathrm{CdCl}_{2}$ binding. Moreover, the CXXC motif was a crucial Cd-binding site in TaSBP-A that could cause significant alterations of the protein's second structure as a result of interaction between TaSBP-A and $\mathrm{Cd}^{2+}$.

\subsection{Functional verification of TaSBP and Cd-binding CXXC motif in wheat protoplasts}

We transformed TaSBP-A and $\triangle T a \Sigma B \Pi-A$ to wheat protoplasts for further function verification of the TaSBP and Cd-binding CXXC motif. Recombinant 16318-TaSBP-A, 16318- $\triangle T a \Sigma B \Pi-A$ and the empty vector $16318 \mathrm{hGFP}$ were transferred into the leaf protoplasts of Chinese Spring, and then they were treated with $50 \mu \mathrm{M} \mathrm{Cd}^{2+}$. The viable protoplasts (yellow light overlapped by chloroplast autofluorescence and GFP green fluorescence) that occurred after transformation were counted (Figure 7a). The transgenic efficiency of the empty vector was approximately $27 \%$, and it remained stable during the whole experiment under normal condition $\left(0 \mu \mathrm{M} \mathrm{Cd}^{2+}\right)$. In turn, $T a \Sigma B \Pi-A / \Delta T a \Sigma B \Pi-A$ had a transgenic efficient of approximately about $20 \%$, serving as the basis to explore the relative rate of the protoplasts' viability (RRPV) under Cd treatment (Figure S5). Compared to TaSBP-A (73\%) and $\Delta T a \Sigma B \Pi-A(56 \%)$, the number of viable protoplasts dramatically dropped after $12 \mathrm{~h}$ of Cd treatment in the empty vector, during which RRPV declined to $25 \%$. The dynamic RRPV was plotted from $0-12 \mathrm{~h}$ under cadmium treatment and it was also

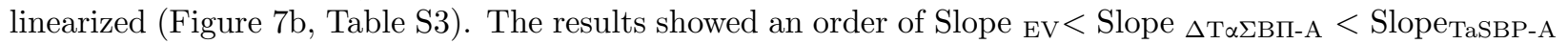
$(-0.06306<-0.04225<-0.02226)$ (Table S3), which indicates that the death rate of protoplasts was EV $>$ $\triangle$ TaSBP-A $>$ TaSBP-A. Compared to TaSBP-A, the dynamic RRPV of $\triangle T a \Sigma B \Pi-A$ transgenic cells during $0-4 \mathrm{~h}$ had no significant difference. However, after $4 \mathrm{~h}$ under Cd stress, the reduction of $\triangle T a \Sigma B \Pi-A \mathrm{RRPV}$ was more palpable than that of TaSBP-A (Figure $7 \mathrm{~b}$ ). These results revealed that the CXXC motif played a key role in TaSBP tolerance to Cd stress, whose mutation can heavily inhibit the ability of TaSBP to interact with $\mathrm{Cd}^{2+}$.

\section{4 | Discussion}

Abiotic stresses are the major environment factors that lead to crop yield reduction. Therefore, it is crucial for the genetic improvement of crop cultivars to discover potential stress-resistant genes and to explore the molecular mechanisms of plant adverse response. Heavy metal Cd severely affects the plant metabolic and physiological processes through elevating ROS (Ranieri et al., 2005) and through cell ultrastructural damages (Chen et al., 2018; Cheng et al., 2018). It can also enter chloroplasts and disturb chloroplast function by inhibiting the enzymatic activities of chlorophyll biosynthesis and the chloroplast structure, which causes a decline of chlorophyll content and photosynthesis (Ying et al., 2010). Meanwhile, excess Cd causes overproduction of MDA contents in both shoots and roots of wheat (Chen et al., 2010). 
Plant SBPs can be induced by various stressors such as $\mathrm{Cd}$, Se, $\mathrm{Cu}, \mathrm{Zn}$, and $\mathrm{H}_{2} \mathrm{O}_{2}$ (Agalou et al., 2005; Dutilleul et al., 2008; Hugouvieux et al., 2009). We found that TaSBP genes may express in different wheat organs; in particular, TaSBP-Adisplayed the highest expression level in the roots (Figure 2a, b). Similar to AtSBP1 in Arabidopsis (Dutilleul et al., 2008; Sarry et al., 2006), TaSBP-A , as a highly hydrophilic cytosolic protein, was highly induced by Cd stress (Figure 3a,b). Its overexpression of yeast (Figure 3c, d), Arabidopsis (Figure 4) and wheat protoplast (Figure 7) conferred Cd-tolerance through Cd accumulation and detoxification. This suggests that the specific Cd-binding site is present in TaSBP-A, and this may interact with $\mathrm{Cd}$ to form a protein complex and, subsequently, to alleviate $\mathrm{Cd}$ toxicity.

The $\mathrm{Cd}$ toxicities are mainly brought up by free $\mathrm{Cd}^{2+}$, which has a high ability to substitute other metals to serve as crucial active centers such as $\mathrm{Cu}$ in SOD and Mg in chlorophyll (Choppala et al., 2014). To date, the binding ability of SBPs to kinds of heavy metal such as $\mathrm{Cd}^{2+}, \mathrm{Zn}^{2+}$ and $\mathrm{Ni}^{2+}$ has been reported by multiple researchers (Dutilleul et al., 2008; Schild et al., 2014). In this study, our results confirmed that an overexpression of $T a S B P-A$ significantly reduced free $\mathrm{Cd}^{2+}$ content. The major existence of over-accumulated $\mathrm{Cd}$ occurred in the Cd-complexes (Figure 5), implying its strong binding ability to $\mathrm{Cd}$. As a cytosolic protein, SBPs have a putative heavy metal binding motif CXXC that is highly conservative among different plant species (Figure S1). This motif contain two free accessible Cys residues on the random coils (Figure 1d), which may facilitate Cd-binding and protein complex formation. A number of proteins containing the CXXC motif have been determined to participate in metal ion metabolism and detoxification; this includes Cd19, MerP and ATX1 (Lin \& Culotta, 1995; Powlowski \& Sahlman, 1999; Suzuki et al., 2002). In this study, we provided sufficient evidence to confirm that the CXXC motif in TaSBP-A is a major Cd-binding site that can interact with $\mathrm{Cd}$ and form a metal complex to reduce the free $\mathrm{Cd}^{2+}$ content and to confer $\mathrm{Cd}$ tolerance. Furthermore, the CXXC motif is able to enhance affinity of TaSBP-A to Cd (Figure 6c, Table 1).

We noticed that the mutation of CXXC to GXXG ( $\Delta$ TaSBP-A) still had Cd-binding ability that led to some alterations of the thermodynamic properties and the secondary structure of the recombinant proteins (Figure 6c, d; Table S2). This suggests that, in addition to the main CXXC binding site in TaSBP-A, other metal binding sites are still likely to be present. It is known that the side-chain carboxylate, sulfur and imidazole groups generally dominate metal coordination in proteins such as histidine, aspartic acid, glutamic acid and cysteine (Tainer et al., 1992). In particular, cysteine residues such as $\mathrm{Cys}^{21} \mathrm{Cys}^{22}$ for Se-binding in AtSBP1 were found to have binding ability (Schild et al., 2014). In addition, TaSBP-A had two more cysteine residues $\left(\mathrm{Cys}^{51}\right.$ and $\mathrm{Cys}^{289}$ ) than did AtSBPs. Thus, it can be excluded from the Cd-binding candidate sites with high probability due to its non-conservative characteristics (Figure S6). The $\beta$-sheet forms the framework for proteins and the loop between two $\beta$-sheets has high flexibility (Chothia et al., 1998). According to the predicted 3-D structure of TaSBP-A (Figure 1d), seven $\beta$-sheets provide the structural framework of TaSBP-A; in turn, this may cause more rigid structure for the residues located on $\beta$-sheet. Thus, the Cys ${ }^{161}$ and $\mathrm{Cys}^{171}$ located on $\beta$-sheet may be less flexible for $\mathrm{Cd}$-binding. The left cysteine residues $\left(\mathrm{Cys}^{23}\right.$, $\mathrm{Cys}^{24}$ and $\mathrm{Cys}^{488}$ ) may serve as the candidate Cd-binding sites. In addition, three His-rich motifs (two HxD and one HxxH) are highly conserved in both TaSBPs and AtSBPs (Figure S6); as such, they may also serve as potential heavy metal binding sites. However, further studies are still needed to determine if this is the case.

Compared to several micro-nutrients including $\mathrm{Zn}, \mathrm{Mn}$ and $\mathrm{Ni}$, Cadmium translocation moves slowly from the root system to the shoot (Choppala et al., 2014). Nearly $50 \%$ of the absorbed Cd is retained in the roots (Obata \& Umebayashi, 1993). Harmful excess metal ions are likely to enter cells through the cation transporters of the root tissues that have broad substrate specificity (Thomine et al., 2000). In order to deal with the damage inflicted by these absorbed metals, plants can produce metallochaperones to maintain appropriate levels of the metal concentration by binding and releasing (Suzuki et al., 2002). Subsequently, the bound metals may be transferred to metal trapping compounds such as phytochelatins, which ultimately detoxify them in vacuoles (Toppi \& Gabbrielli, 1999). In this study, we found that the overexpression of $T a S B P-A$ can cause higher absorption rates of $\mathrm{Cd}^{2+}$ as well as $\mathrm{Cd}^{2+}$-locking under the hypocotyl of plant roots. Thus, TaSBP-A may serve as a cytoplasmic heavy metal transporter (metallochaperones) to help accelerate metal ion transport into the vacuole since the SBP56 family protein has a transport function that is involved in intra-Golgi protein transport (Porat et al., 2000). 
In conclusion, as a cytoplasmic protein and typical SBP56 family member, TaSBP-A highly expressed in plant roots and it was highly induced by Cd stress. The overexpression of TaSBP-A conferred Cd-tolerance in yeast, Arabidopsis and wheat protoplasts through the uptake and detoxification of free $\mathrm{Cd}^{2+}$. The CXXC motif in TaSBP-A was confirmed as a major Cd-binding site via an in vitro $\mathrm{Cd}^{2+}$ binding assay combined with a thermodynamics survey and a secondary structure analysis. Its mutation not only decreased a one binding site of TaSBP-A, but also significantly reduced the affinity of other binding sites in TaSBP-A to Cd. The interaction between the CXXC motif and $\mathrm{Cd}$ as well as the metal protein complex formation enhanced the absorption and detoxification of free $\mathrm{Cd}^{2+}$, ultimately conferring plant Cd-tolerance (Figure 8).

\section{ACKNOWLEDGMENTS}

This research was financially supported by grants from the National Key R \& D Program of China (2016YFD0100502). The English in this document has been checked by at least two professional editors, both native speakers of English. For a certificate, please see:https://submit.proofreadingmanuscripts.com/getstarted.

\section{CONFLICT OF INTERESTS}

The authors declare that there are no conflicts of interest.

\section{AUTHOR CONTRIBUTIONS}

Yueming Yan designed the experiments; Fei Luo, Dong Zhu and Rong Zou performed most of the experiments; Wenjing Duan performed the skillful technical experiments in confocal microscope.

\section{REFERENCE}

Agalou, A., Roussis, A., \& Spaink, H. P. (2005). The Arabidopsis selenium-binding protein confers tolerance to toxic levels of selenium.Functional Plant Biology , 32 (10), 881-890. https://doi.org/10.1071/FP05090

Arasimowicz-Jelonek, M., Floryszak-Wieczorek, J., \& Gwóźdź, E. A. (2011). The message of nitric oxide in cadmium challenged plants.Plant Science , 181 (5), 612-620. https://doi.org/10.1016/j.plantsci.2011.03.019

Bansal, M. F., Mukhopadhyay, T., Scott, J., Cook, R. G., Mukhopadhyay, R., \& Medina, D. (1990). DNA sequencing of a mouse liver protein that binds selenium: implications for selenium's mechanism of action in cancer prevention. Carcinogenesis , 11 (11), 2071-2073. https://doi.org/10.1093/carcin/11.11.2071

Bansal, M. P., Oborn, C. J., Danielson, K. G., \& Medina, D. (1989). Evidence for two seleniumbinding proteins distinct from glutathione peroxidase in mouse liver. Carcinogenesis , 10 (3), 541-546. https://doi.org/10.1093/carcin/10.3.541

Chen, C. H., Zhou, Q. X., Cai, Z., \& Wang, Y. Y. (2010). Effects of soil polycyclic musk and cadmium on pollutant uptake and biochemical responses of wheat (Triticum aestivum ). Archives of Environmental Contamination and Toxicology, 59 (4), 564-573. https://doi.org/10.1007/s00244-010-9522-5

Chen, Z., Zhu, D., Wu, J., Cheng, Z., Yan, X., Deng, X., \& Yan, Y.M. (2018). Identification of differentially accumulated proteins involved in regulating independent and combined osmosis and cadmium stress response in Brachypodium seedling roots. Scientific Reports , 8 (1), 1-17. https://doi.org/ 10.1038/s41598-018-259598

Cheng, Z. W., Chen, Z. Y., Yan, X., Bian, Y. W., Deng, X., \& Yan, Y. M. (2018). Integrated physiological and proteomic analysis reveals underlying response and defense mechanisms of Brachypodium distachyon seedling leaves under osmotic stress, cadmium and their combined stresses. Journal of Proteomics , 170 , 1-13. https://doi.org/10.1016/j.jprot.2017.09.015 
Chmielowska-Bak, J., Gzyl, J., Rucińska-Sobkowiak, R., Arasimowicz-Jelonek, M., \& Deckert, J. (2014). The new insights into cadmium sensing. Frontiers in Plant Science, 5(245), 1-14. https://doi.org/10.3389/fpls.2014.00245

Choppala, G., Saifullah, Bolan, N., Bibi, S., Iqbal, M., Rengel, Z., Kunhikrishnan, Anitha., Ashwath, Nanjappa., Ok, Y. S. (2014). Cellular mechanisms in higher plants governing tolerance to cadmium toxicity. Critical Reviews in Plant Sciences , 33 (5), 374-391. https://doi.org/10.1080/07352689.2014.903747

Chothia, C., Gelfand, I., \& Kister, A. (1998). Structural determinants in the sequences of immunoglobulin variable domain. Journal of Molecular Biology , 278 (2), 457-479. https://doi.org/10.1006/jmbi.1998.1653

Culotta, V. C., Klomp, L. W. J., Strain, J., Casareno, R. L. B., Krems, B., \& Gitlin, J. D. (1997). The copper chaperone for superoxide dismutase. Journal of Biological Chemistry , 272 (38), 23469-23472. https://doi.org/10.1074/jbc.272. 38.23469

Curie, C., Gaëlle, C., Daniel, C., Fanchon, D., Kyoko, H., Marie, L.J., Julie, M., Adam, S., Pierre, C., Stéphane, M. (2009). Metal movement within the plant: contribution of nicotianamine and yellow stripe 1-like transporters. Annals of Botany , 103 (1), 1-11. https://doi.org/10.1093/aob/mcn207

Dai, X., Feng, L., Ma, X., \& Zhang, Y. (2012). Concentration level of heavy metals in wheat grains and the health risk assessment to local inhabitants from Baiyin, Gansu, China. Advanced Materials Research, 518 -523 , 951-956. https://doi.org/ 10.4028/www.scientific.net/AMR.518-523.951

Dutilleul, C., Jourdain, A., Bourguignon, J., \& Hugouvieux, V. (2008). The Arabidopsis putative seleniumbinding protein family: expression study and characterization of SBP1 as a potential new player in cadmium detoxification processes. Plant Physiology , 147 (1), 239-251. https://doi.org/10.1104/ pp.107.114033

Fatima, G., Raza, A. M., Hadi, N., Nigam, N., \& Mahdi, A. A. (2019). Cadmium in human diseases: It's more than just a mere metal.Indian Journal of Clinical Biochemistry , 34, 371-378. https://doi.org/10.1007/s12291-019-00839-8

Flemetakis, E., Agalou, A., Kavroulakis, N., Dimou, M., Martsikovskaya, A., Slater, A., Spaink, H., Roussis, A., Katinakis, P. (2002). Lotus japonicus gene Ljsbp is highly conserved among plants and animals and encodes a homologue to the mammalian selenium-binding proteins. Molecular Plant-Microbe Interactions , 15 (4), 313-322. https://doi.org/10.1094/MPMI.2002.15.4.313

Huamain, C., Chunrong, Z., Cong, T., \& Yongguan., Z. (1999). Heavy metal pollution in soils in China: status and countermeasures.Ambio , 28 (2), 130-134. Retrieved from http://www.jstor.org/stable/4314863

Hugouvieux, V., Dutilleul, C., Jourdain, A., Reynaud, F., Lopez, V., \& Bourguignon, J. (2009). Arabidopsis putative selenium-binding protein 1 expression is tightly linked to cellular sulfur demand and can reduce sensitivity to stresses requiring glutathione for tolerance. Plant Physiology , 151 (2), 768-781. https://doi.org/ 10.1104/pp.109.144808

Ismael, M. A., Elyamine, A. M., Moussa, M. G., Cai, M., Zhao, X., \& Hu, C. (2019). Cadmium in plants: uptake, toxicity, and its interactions with selenium fertilizers. Metallomics , 11 (2), 255-277. https://doi.org/10.1039/c8mt00247a

Landsberg, P. T. (1984). Can entropy and "order" increase together? Physics LettersA , 102 (4), 171-173. https://doi.org/10.1016/0375-9601(84)90934-4

Lang, I., \& Wernitznig, S. (2011). Sequestration at the cell wall and plasma membrane facilitates zinc tolerance in the moss Pohlia drummondii. Environmental and Experimental Botany , 74 (1), 186-193. https://doi.org/ 10.1016/j.envexpbot.2011.05.018

Lei, G. J., Fujii-Kashino, M., Wu, D. Z., Hisano, H., Saisho, D., Deng, F., Yamaji, N., Sato, K., Zhao, F.J., Ma, J. F. (2020). Breeding for low cadmium barley by introgression of a Sukkula-like transposable element.Nature Food , 1 (8), 489-499. https://doi.org/10.1038/s43016-020-0130-x 
Leita, L., De Nobili, M., Cesco, S., \& Mondini, C. (1996). Analysis of intercellular cadmium forms in roots and leaves of bush bean. Journal of Plant Nutrition , 19 (3-4), 527-533. https://doi.org/10.1080/01904169609365140

Li, Q., Zhang, X., Lv, Q., Zhu, D., Qiu, T., Xu, Y., Bao, F., He, Y.K., Hu, Y. (2017). Physcomitrella patens dehydrins (PpDHNA and PpDHNC) confer salinity and drought tolerance to transgenic Arabidopsis plants. Frontiers in Plant Science ,8 (1316), 1-15. https://doi.org/10.3389/fpls.2017.01316

Li, Y., Chen, Z., Xu, S., Zhang, L., Hou, W., \& Yu, N. (2015). Effect of combined pollution of Cd and B[a]P on photosynthesis and chlorophyll fluorescence characteristics of wheat. Polish Journal of Environmental Studies , 24 (1), 157-163. https://doi.org/10.15244/pjoes/22274

Lin, S. J., \& Culotta, V. C. (1995). The ATX1 gene of Saccharomyces cerevisiae encodes a small metal homeostasis factor that protects cells against reactive oxygen toxicity. Proceedings of the National Academy of Sciences of the United States of America , 92 (9), 3784-3788. https://doi.org/10.1073/pnas.92.9.3784

Lin, T., Yang, W., Lu, W., Wang, Y., \& Qi, X.T (2017). Transcription factors PvERF15 and PvMTF-1 form a cadmium stress transcriptional pathway. Plant Physiology , 173 (3), 1565-1573. https://doi.org/10.1155/2016/9739505

López-Luna, J., Silva-Silva, M. J., Martinez-Vargas, S., Mijangos-Ricardez, O. F., González-Chávez, M. C., Solís-Domínguez, F. A., \& Cuevas-Díaz, M. C. (2015). Magnetite nanoparticle (NP) uptake by wheat plants and its effect on cadmium and chromium toxicological behavior. Science of the Total Environment , 565 (15), 941-950. https://doi.org/10.1016/j.scitotenv.2016.01.029

Lu, L. L., Tian, S. K., Yang, X. E., Wang, X. C., Brown, P., Li, T. Q., \& He, Z. L. (2008). Enhanced root-to-shoot translocation of cadmium in the hyperaccumulating ecotype of Sedum alfredii . Journal of Experimental Botany , 59 (11), 3203-3213. https://doi.org/10.1093/jxb/ern174

Luo, J. S., Yang, Y., Gu, T., Wu, Z., \& Zhang, Z. (2019). The Arabidopsis defensin gene AtPDF2.5 mediates cadmium tolerance and accumulation. Plant Cell and Environment . https://doi.org/10.1111/pce.13592

Ma, J., Cai, H., He, C., Zhang, W., \& Wang, L. (2015). A hemicellulose-bound form of silicon inhibits cadmium ion uptake in rice (Oryza sativa) cells. New Phytologist , 206 (3), 1063-1074. https://doi.org/10.1111/nph.13276

Maher, W., Forster, S., Krikowa, F., Snitch, P., Chapple, G., \& Craig, P. (2001). Measurement of trace elements and phosphorus in marine animal and plant tissues by low-volume microwave digestion and ICPMS.Atomic Spectroscopy , 22 (5), 360-371. https://doi.org/10.1366/0003702011953324

Obata, H., \& Umebayashi, M. (1993). Production of SH compounds in higher plants of different tolerance to Cd. Plant and Soil ,155-156 (1), 533-536. https://doi.org/10.1007/BF00025101

Porat, A., Sagiv, Y., \& Elazar, Z. (2000). A 56-kDa selenium-binding protein participates in intra-Golgi protein transport. Journal of Biological Chemistry , 275 (19), 14457-14465. https://doi.org/10.1074/jbc.275.19.14457

Powlowski, J., \& Sahlman, L. (1999). Reactivity of the two essential cysteine residues of the periplasmic mercuric ion-binding protein, MerP.Journal of Biological Chemistry , 274 (47), 33320-33326. https://doi.org/10.1074/jbc.274.47.33320

Ranieri, A., Castagna, A., Scebba, F., Careri, M., Zagnoni, I., Predieri, G., Pagliari, M., Di Toppi, L. S. (2005). Oxidative stress and phytochelatin characterisation in bread wheat exposed to cadmium excess. Plant Physiology and Biochemistry , 43 (1), 45-54. https://doi.org/10.1016/j.plaphy.2004.12.004

Rizwan, M., Meunier, J. D., Miche, H., \& Keller, C. (2012). Effect of silicon on reducing cadmium toxicity in durum wheat (Triticum turgidum L. cv. Claudio W.) grown in a soil with aged contamination. Journal of Hazardous Materials , 209 -210 , 326-334. https://doi.org/10.1016/j.jhazmat.2012.01.033 
Sanità Di Toppi, L., \& Gabbrielli, R. (1999). Response to cadmium in higher plants. Environmental and Experimental Botany ,41 (2), 105-130. https://doi.org/ 10.1016/S0098-8472(98)00058-6

Saraswat, S., \& Rai, J. P. N. (2011). Complexation and detoxification of Zn and Cd in metal accumulating plants. Reviews in Environmental Science and Biotechnology , 10 , 327-339. https://doi.org/10.1007/s11157011-9250-y

Sarry, J.-E., Kuhn, L., Ducruix, C., Lafaye, A., Junot, C., Hugouvieux, V., Jourdain, A., Bastien, O., Fievet, J.B., Vailhen, D., Amekraz, B., Moulin, C., Ezan, E., Garin, J., Bourguignon, J. (2006). The early responses of Arabidopsis thaliana cells to cadmium exposure explored by protein and metabolite profiling analyses. Proteomics ,6 (7), 2180-2198. https://doi.org/10.1002/pmic.200500543

Sarwar, N., Saifullah, Malhi, S. S., Zia, M. H., Naeem, A., Bibia, S., \& Farida, G. (2010). Role of mineral nutrition in minimizing cadmium accumulation by plants. Journal of the Science of Food and Agriculture, 90 (6), 925-937. https://doi.org/10.1002/jsfa.3916

Sawada, K., Hasegawa, M., Tokuda, L., Kameyama, J., Kodama, O., Kohchi, T., Yoshida, K., Shinmyo, A. (2004). Enhanced resistance to blast fungus and bacterial blight in transgenic rice constitutively expressing $O s S B P$, a rice homologue of mammalian selenium-binding proteins.Bioscience, Biotechnology, and Biochemistry , 68 (4), 873-880. https://doi.org/10.1271/bbb.68.873

Schild, F., Kieffer-Jaquinod, S., Palencia, A., Cobessi, D., Sarret, G., Zubieta, C., Jourdain, A., Dumas, R., Forge, V., Testemale, D., Bourguignon, J., Hugouvieux, V. (2014). Biochemical and biophysical characterization of the selenium-binding and reducing site in Arabidopsis thaliana homologue to mammals selenium-binding protein 1.Journal of Biological Chemistry , 289 (46), 31765-31776. https://doi.org/10.1074/jbc.M114.571208

Schreiber, U., Quayle, P., Schmidt, S., Escher, B. I., \& Mueller, J. F. (2007). Methodology and evaluation of a highly sensitive algae toxicity test based on multiwell chlorophyll fluorescence imaging. Biosensors and Bioelectronics ,22 (11), 2554-2563. https://doi.org/10.1016/j.bios.2006.10.018

Suzuki, N., Yamaguchi, Y., Koizumi, N., \& Sano, H. (2002). Functional characterization of a heavy metal binding protein CdI19 from Arabidopsis. The Plant Journal , 32 , 165-173. https://doi.org/10.1046/j.1365313X.2002.01412.x

Tainer, J. A., Roberts, V. A., \& Getzoff, E. D. (1992). Protein metal-binding sites. Current Opinion in Biotechnology ,3 (4), 378-387. https://doi.org/10.1016/ 0958-1669(92)90166-G

Thomine, S., Wang, R., Ward, J. M., Crawford, N. M., \& Schroeder, J. I. (2000). Cadmium and iron transport by members of a plant metal transporter family in Arabidopsis with homology to Nramp genes.Proceedings of the National Academy of Sciences of the United States of America , 97 (9), 4991-4996. https://doi.org/10.1073/pnas.97.9.4991

Wu, H., Chen, C., Du, J., Liu, H., Cui, Y., Zhang, Y., He, Y., Wang, Y., Chu, C., Feng, Z., Li, J., Ling, H. Q. (2012). Co-overexpression FIT withAtbHLH38 or AtbHLH39 in Arabidopsis enhanced cadmium tolerance via increased cadmium sequestration in roots and improved iron homeostasis of shoots. Plant Physiology , 158 (2), 790-800. https://doi.org/10.1104/pp.111.190983

Yan, H., Xu, W., Xie, J., Gao, Y., Wu, L., Sun, L., Feng, L., Chen, X., Zhang, T., Dai, C., Li, T., Lin, X., Zhang, Z., Wang, X., Li, F., Zhu, X., Li, J., Li, Z., Chen, C., Ma, M., Zhang, H., He, Z. (2019). Variation of a major facilitator superfamily gene contributes to differential cadmium accumulation between rice subspecies. Nature Communications , 10 (1), 1-12. https://doi.org/10.1038/s41467-019- 10544-y

Yang, J. K., \& Davis, A. P. (1999). Competitive adsorption of Cu(II)-EDTA and Cd(II)-EDTA onto TiO2. Journal of Colloid and Interface Science, 216 (1), 77-85. https://doi.org/10.1006/jcis.1999.6278

Yang, J. T., Wu, C. S. C., \& Martinez, H. M. (1986). Calculation of protein conformation from circular dichroism. Methods in Enzymology , 130 , 208-269. https://doi.org/10.1016/0076-6879(86)30013-2 
Yang, W., \& Diamond, A. M. (2013). Selenium-binding protein 1 as a tumor suppressor and a prognostic indicator of clinical outcome.Biomarker Research , 1 (1), 1-4. https://doi.org/10.1186/2050-7771-1-15

Ying, R. R., Qiu, R. L., Tang, Y. T., Hu, P. J., Qiu, H., Chen, H. R., Shi, T.H., Morel, J. L. (2010). Cadmium tolerance of carbon assimilation enzymes and chloroplast in $\mathrm{Zn} / \mathrm{Cd}$ hyperaccumulator Picris divaricata. Journal of Plant Physiology ,167 (2), 81-87. https://doi.org/10.1016/j.jplph.2009.07.005

Yu, Y., Zhu, D., Ma, C., Cao, H., Wang, Y., Xu, Y., Zhang, W., Yan, Y. (2016). Transcriptome analysis reveals key differentially expressed genes involved in wheat grain development. Crop Journal , 4 (2), 92-106. https://doi.org/10.1016/ j.cj.2016.01.006

Yuan, D. S., Stearman, R., Dancis, A., Dunn, T., Beeler, T., \& Klausner, R. D. (1995). The Menkes/Wilson disease gene homologue in yeast provides copper to a ceruloplasmin-like oxidase required for iron uptake. Proceedings of the National Academy of Sciences of the United States of America , 92 (7), 2632-2636. https://doi.org/10.1073/pnas.92.7.2632

Zhang, L., Gao, C., Chen, C., Zhang, W., Huang, X.-Y., \& Zhao, F.-J. (2020). Overexpression of riceOsHMA3 in wheat greatly decreases cadmium accumulation in wheat grain. Environmental Science 83 Technology , 54 (16), 10100-10108. https://doi.org/10.1021/acs.est.0c02877

Zhang, M., Lv, D., Ge, P., Bian, Y., Chen, G., Zhu, G., Li, X., Yan, Y. (2014). Phosphoproteome analysis reveals new drought response and defense mechanisms of seedling leaves in bread wheat (Triticum aestivum L.). Journal of Proteomics , 109 , 290-308. https://doi.org/10.1016/j.jprot.2014.07.010

Zhou J., \& Goldsbrough, P. B. (1994). Functional homologs of fungal metallothionein genes from Arabidopsis. Plant Cell , 6 (6), 875-884. https://doi.org/10.1105/ tpc.6.6.875

Zou, R., Wu, J., Wang, R., \& Yan, Y. (2020). Grain proteomic analysis reveals central stress responsive proteins caused by wheat-Haynaldia villosa $6 \mathrm{VS} / 6 \mathrm{AL}$ translocation. Journal of Integrative Agriculture . 2020, 19(11) , 2-16. http://creativecommons.org/licenses/by-nc-nd/4.0/

Table 1 Thermodynamic parameters calculated from micro-calorimetric experiments for the interaction between $\mathrm{Cd}^{2+}$ and TaSBP-A/ $\Delta$ TaSBP-A at $25^{\circ} \mathrm{C}(298.15 \mathrm{~K})$ in $10 \mathrm{mM}$ HEPES, $\mathrm{pH} 7.4,150 \mathrm{mM} \mathrm{NaCl}$.

\begin{tabular}{llllll}
\hline Proteins & $\mathrm{K}\left(\mathrm{M}^{-1}\right)$ & $\Delta \mathrm{H}(\mathrm{kcal} / \mathrm{mol})$ & $\Delta \mathrm{H}(\mathrm{kcal} / \mathrm{mol})$ & $\Delta \mathrm{S}(\mathrm{cal} / \mathrm{mol} / \mathrm{K})$ & $\Delta \mathrm{G}(\mathrm{kcal} / \mathrm{mol})$ \\
\hline TaSBP-A & $(33.2 \pm 3.49) \times 10^{3}$ & $(33.2 \pm 3.49) \times 10^{3}$ & $-17.92 \pm 1.93$ & -39.4 & $-6.17 \pm 1.93$ \\
$\Delta$ TaSBP-A & $(20.7 \pm 1.51) \times 10^{3}$ & $(20.7 \pm 1.51) \times 10^{3}$ & $-13.30 \pm 1.11$ & -24.9 & $-5.88 \pm 1.12$ \\
\hline
\end{tabular}

\section{Figure legends:}

FIGURE 1 Phylogenetics and structural characterization of wheat TaSBPs. (a) Phylogenetic relationships between TaSBP-A/B/D protein and other SBPs of various species. (b) Simplified illustration of TaSBP protein structure. One putative metal binding region (HMR) and one Selenium-binding region (SBR) are shown. (c) Protein sequences containing the CXXC-type metal binding domain were obtained from GenBank. Accession numbers are ATX1 (P38636), CHF (AAC33510), ATFP3 (AAD09507) and Cd19 (AAM64219.1). The core sequence of the metal binding region is CXXC ( $\mathrm{C}$ is cysteine and $\mathrm{X}$ is any amino acid). (d) 3-D structure of TaSBP-A based on the structure of $S$. tokodaii (SMTL ID: 2ece.1).

FIGURE 2 Transcriptional expression profiling of TaSBPs in different wheat organs and the subcellular localization of TaSBP-A. (a) The heat map of TaSBP's expression in the root, stem and leaf of wheat seedings. (b) TaSBP-A expression in different organs of Chinese Spring at the three-leaf stage. (c) Subcellular distribution of the 35S-TaSBP-GFP fusion proteins in wheat protoplasts as shown by using confocal laser scanning microscope. The red is the chloroplast fluorescence and the green is the GFP fluorescence. 
FIGURE 3 TaSBP-A responding to Cd-stress in Chinese Spring roots and its overexpression in Saccharomyces cerevisiae DEY1457. Wheat seedlings were treated with $50 \mu \mathrm{M} \mathrm{CdCl} 2$ for 24,48 and $72 \mathrm{~h}$ during the threeleaf stage. (a) Transcription expression by RT-qPCR. (b) Protein accumulation by Western blot. (c) Serial dilutions of the $S$. cerevisiae strains expressing the pYES2.0 empty vector (EV); a pYES2 harbouring one of the TaSBP-A spotted on medium supplemented with 0 (control) or $30 \mu \mathrm{M} \mathrm{CdCl}_{2}$, as indicated above the panels. Each spot is comprised by $5 \mu \mathrm{l}$ of a yeast culture diluted at the optical density at $600 \mathrm{~nm}$ (OD600 $=2.0$ is the first spot). (d) Cd content of harvested cells measured by ICP-MS. The data were statistically analyzed using a one-way ANOVA. The asterisks indicate significant differences at different levels $\left({ }^{*} p<0.05 ;{ }^{* *} p<0.01 ;{ }^{* * *} p<0.001\right)$.

FIGURE 4 Overexpressed TaSBP-A in Arabidopsis thalianaenhanced Cd-tolreance. (a) Phenotypic comparison of the wild type and transgenic Arabidopsis lines (S2-9, S3-12, and S4-7) under Cd stress. Three-week-old plants were watered with150 $\mu \mathrm{M} \mathrm{CdCl}_{2}$ once a week for four weeks. Control group (CK) was normally irrigated with water. (b-d) Changes of SOD activity, $\mathrm{H}_{2} \mathrm{O}_{2}$ and the MDA content of transgenic Arabidopsis and the wild type (WT). (e) Total Cd content changes in the transgenic and wild type lines. (f) Chlorophyll fluorescence changes of the efficiency of PSII in the light (ФPSII), and the inhibition of the PSII quantum yield (Inh) of WT and overexpressed Arabidopsis lines. (g-i) Changes of chlorophyll fluorescence parameters Fv/Fm (g), ФPSII (h), and Inh (i) extracted from fluorescence images. (j) Chlorophyll content changes of $\mathrm{WT}$ and the transgenic line under Cd stress. The data are indicated as mean \pm SD from three biological replicates. All data were statistically analyzed using a one-way ANOVA. The asterisks indicate significant differences at different levels $\left({ }^{*} p<0.05 ;{ }^{* *} p<0.01 ;{ }^{* * *} p<0.001\right)$.

FIGURE $5 \mathrm{Cd}^{2+}$ fluxes and free $\mathrm{Cd}^{2+}$ detection in TaSBP-A overexpressed Arabidopsis root hairs. (a) A representative root hair and the $\mathrm{Cd}^{2+}$-selective microelectrode used. (b) The mean $\mathrm{Cd}^{2+}$ fluxes in the root hair was measured for $30 \mathrm{~min}$ after exposure to $30 \mu \mathrm{M} \mathrm{Cd}^{2+}$ by using a noninvasive micro-test technique. The data are indicated as mean \pm SD from the three biological replicates. All data were statistically analyzed using a one-way ANOVA. The asterisks indicate significant differences at different levels $\left({ }^{*} p<0.05 ;{ }^{* *} p\right.$ $<0.01 ;{ }^{* * *} p<0.001$ ). (c) Micrographs of seedling roots from WT and overexpressed lines exposed to $150 \mu \mathrm{M}$ $\mathrm{Cd}$ for different periods. Plant roots were pre-treated with $150 \mu \mathrm{M} \mathrm{Cd}$ for $0 \mathrm{~h}$ (control), $6 \mathrm{~h}$ and $12 \mathrm{~h}$ on a 1/2-MS plate and loaded with Leadamium ${ }^{\mathrm{TM}} \mathrm{Green} \mathrm{AM}$ dye for $60 \mathrm{~min}$. All images were taken using a confocal laser scanning microscope (Leica TCS SP5, Germany). Green fluorescence represents the binding of the dye to $\mathrm{Cd}$.

FIGURE 6 Determination of the Cd-binding site in TaSBP-A by in vitro $\mathrm{Cd}^{2+}$ binding assay. (a) $\mathrm{Cd}^{2+}$ binding shift performed with $100 \mu \mathrm{M}$ recombinant proteins and $0.5 \mathrm{mM} \mathrm{Cd}^{2+}$ in vitro. Tris- $\mathrm{HCl}$ was used as a reaction buffer and EDTA was used as a competitive inhibitor to protein. (b) The Cd/Protein Ratio determined by ICP-MS. (c) Isothermal titration calorimetry experiments of the recombinant TaSBP-A (left) and $\triangle$ TaSBP-A (right) binding to $\mathrm{Cd}$. The top panel shows the titration of $\mathrm{Cd}^{2+}$ at $0.5 \mathrm{mM}$ into TaSBP-A $(\triangle$ TaSBP-A) at $50 \mu \mathrm{M}$ placed at the sample cell; the bottom panel shows the ligand concentration dependence of the heat released upon binding after normalization. The data were fitted with the one-site binding model. The data are means \pm SD from the three biological replicates. (d) CD spectra of the recombinant TaSBP-A (left) and $\Delta$ TaSBP-A (right) in the presence of a stepped Cd concentration $(0-4 \mathrm{nmol} \mathrm{Cd})$ at 25 . The protein content remained $1 \mathrm{nmol} / 250 \mu \mathrm{L}$ during the whole experiment. The $\mathrm{X}$ and $\mathrm{Y}$ axes represent the wavelength $(\mathrm{nm})$ and $\mathrm{Y}(\mathrm{mdeg})$, respectively.

FIGURE 7 Overexpressed TaSBP-A in wheat protoplast and Cd-tolerance analysis. (a) The viability of the wheat protoplasts at $12 \mathrm{~h}$ after treatment with $50 \mu \mathrm{M}$ Cd. The $16318 \mathrm{hGFP}$ empty vector, 16318-TaSBP-A and 16318- $\triangle \mathrm{Ta} \Sigma B \Pi-A$ were transformed into wheat protoplasts and then treated with $50 \mu \mathrm{M} \mathrm{Cd}{ }^{2+}$. All images were taken using a Leica TCS SP5. The viable protoplasts appear yellow due to the overlay of both red (chloroplast autofluorescence) and green (GFP); the non-viable protoplasts appear red from the chloroplast autofluorescence. (b) The relative rate of wheat protoplasts' viability accompanied with yellow at $0-12 \mathrm{~h}$ under $50 \mu \mathrm{M} \mathrm{Cd}$ treatment. The CK group was cultured without Cd. All data were statistically analyzed using a one-way ANOVA. The asterisks indicate significant differences at different levels $\left({ }^{*} p<0.05\right.$; 
$* * p<0.01 ; * * * p<0.001)$.

FIGHRE 8 Schematic representation of TaSBP-A involved in Cd-binding and detoxification in plants.

\section{SUPPORTING INFORMATION}

FIGURE S1 Multiple sequence alignments of the deduced amino acid of the SBP proteins of various species. The alignment was performed using the ClustalW method. The asterisks indicate identical residues while gaps in the alignment are represented by dashes. The similarity in wheat of TaSBP-A with TaSBP-B and TaSBP-D is $98.59 \%$ and $97.37 \%$, respectively. The SBP proteins from different organisms were highly conserved. Os (Oryza sativa subsp, Q8RZW7), At (Arabidopsis thaliana, O23264, Q93WN0, Q9LK38), Mm (Mus musculus, P17563), Hs (Homo sapiens, Q13228), Bt (Bos Taurus, Q2KJ32), Xl (Xenopus laevis , Q52KZ7), Pa (Pongo abelii, Q5RF48), Dr (Danio rerio, Q6PHD9) and Rn (Rattus norvegicus, Q8VIF7).

FIGURE S2 Identification of TaSBP-A overexpressedArabidopsis thaliana . (a) A pair of chimeric primers were designed to verify the integration of TaSBP-A into Arabidopsis's genome. PCR was performed with the template strand of Arabidopsis's genome. (b) The protein level of TaSBP-A in the transgenic lines was validated using Western blot.

FIGURE S3 Estimation of the Cd-tolerance of TaSBP-A overexpressed Arabidopsis seedlings. (a) Phenotypic observation of wild type and TaSBP-A transgenic seedlings (S2-9, S3-12 and S4-7). Five-day-old seedlings were treated with different $\mathrm{CdCl}_{2}$ concentrations (0-150 $\left.\mu \mathrm{M} \mathrm{Cd}\right)$ for 7 days. (b) The relative fresh weight of plants under Cd stress. (c) The relative root length of plants under Cd stress. (d) The survival rate of $T a S B P-A$ transgenic and wild type seeds on 1/2 MS containing different $\mathrm{CdCl}_{2}(0-150 \mu \mathrm{M})$. (e) Total Cd content of 5-day-old seedlings of the transgenic and wild type lines with 75 and $150 \mu \mathrm{M} \mathrm{Cd}$ treatments for 7 $\mathrm{d}$, as determined by ICP-MS. The data are shown in mean values \pm SD. All data were statistically analyzed using a one-way ANOVA. The asterisks indicate significant differences at different levels $\left({ }^{*} p<0.05 ;{ }^{* *} p\right.$ $<0.01 ; * * *<0.001)$.

FIGURE S4 Illustration of the recombinant TaSBP-A and $\triangle$ TaSBP-A proteins and the subcellular localization of $\triangle$ TaSBP-A. (a) Schematic diagrams of the recombinant proteins containing the metal binding regions of TaSBP-A and mutant ( $\triangle$ TaSBP-A) expressed in E. coli . The mutant ( $\Delta$ TaSBP-A) contains displaced Cys with Gly in the metal binding regions. (b) Subcellular distribution of the 35S- $\Delta$ TaSBP-GFP fusion proteins in Chinese Spring leaf protoplasts, observed using a confocal laser scanning microscope. The red is chloroplast fluorescence and the green is GFP fluorescence.

FIGURE S5 The viability of wheat protoplasts during $0-12 \mathrm{~h}$ after treatment with $50 \mu \mathrm{M} \mathrm{Cd}$. The $16318 \mathrm{hGFP}$ empty vector, 16318- TaSBP-A and 16318- $\triangle T a \Sigma B \Pi-A$ were transformed into wheat protoplasts and then treated with $50 \mu \mathrm{M} \mathrm{Cd}^{2+}$. All images were taken by Leica TCS SP5. The viable protoplasts appear yellow due to the overlay of red (chloroplast autofluorescence) and green (GFP); non-viable protoplasts appear red (reflecting only chloroplast autofluorescence).

FIGURE S6 Comparison of the potential amino acid sequences of SBP proteins that may serve as heavy metal binding sites. The alignment was performed using the ClustalW method. The asterisks indicate identical residues while gaps in the alignment are represented by dashes. The witnessed CSSC sequence motif is highlighted in red and the putative metal-binding sites $\mathrm{HxD}$ and $\mathrm{HxxH}$ are highlighted in blue. Additional conserved Cys residues are highlighted in green while His residues are highlighted in yellow.

Table S1 The information of primers for PCR, RT-qPCR and site-directed mutation.

Table S2 Effects of Cd-binding on the secondary structure of TaSBP-A and $\Delta$ TaSBP-A proteins

Table S3 Linearization of data in Figure 7b. 
(a)

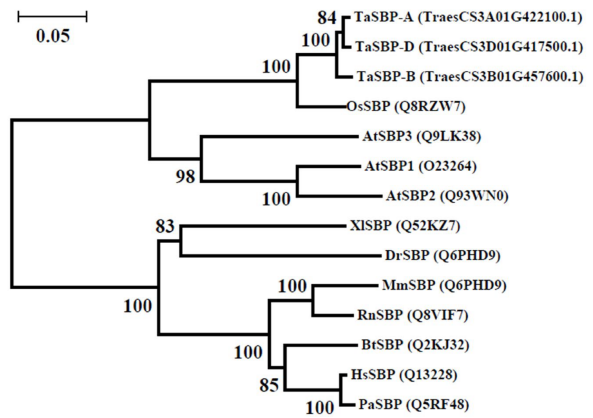

(c)

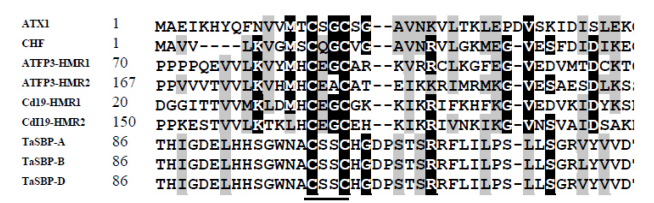

(a)

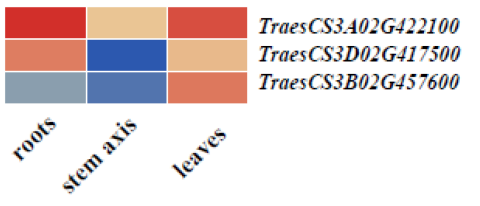

IraesCS3A02G422100 ThesCSBD02G417500

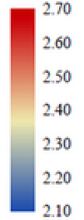

(b)

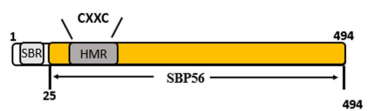

(d)
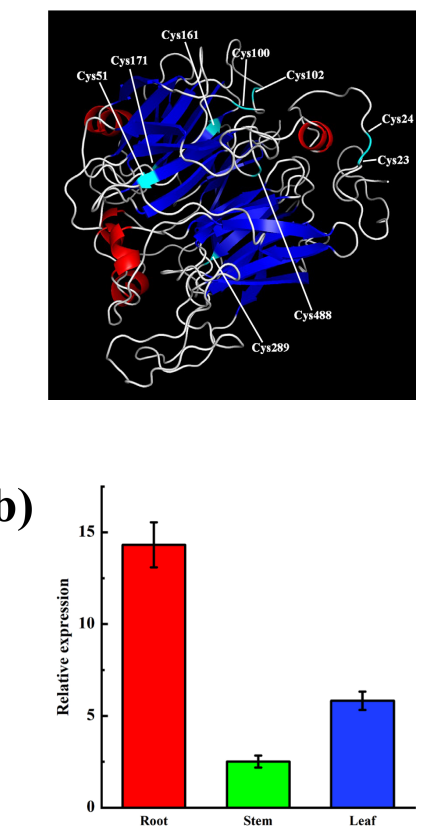

(c)

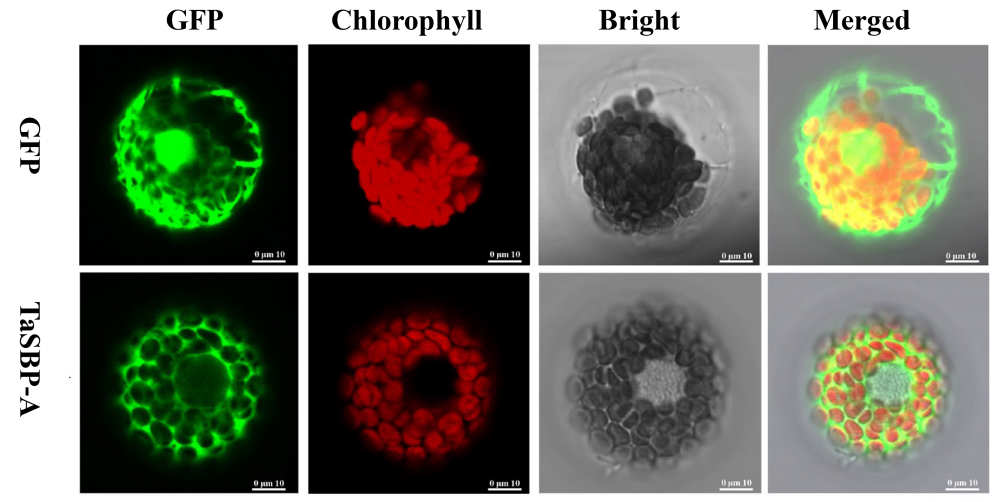


(a)

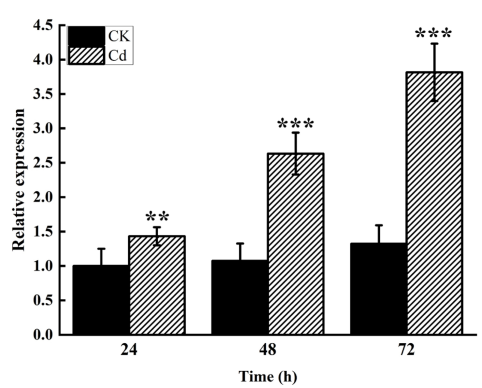

(c)

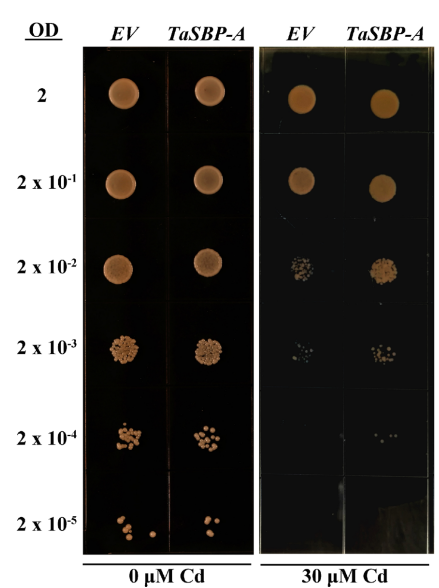

(b)

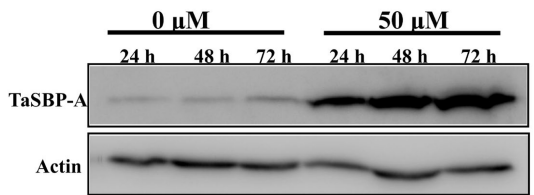

(d)

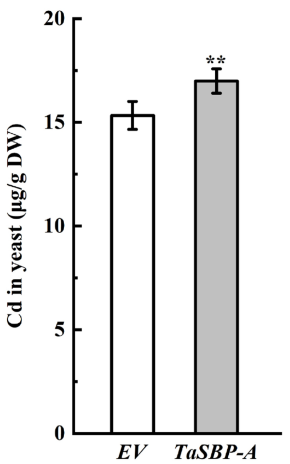

(a)

(f)
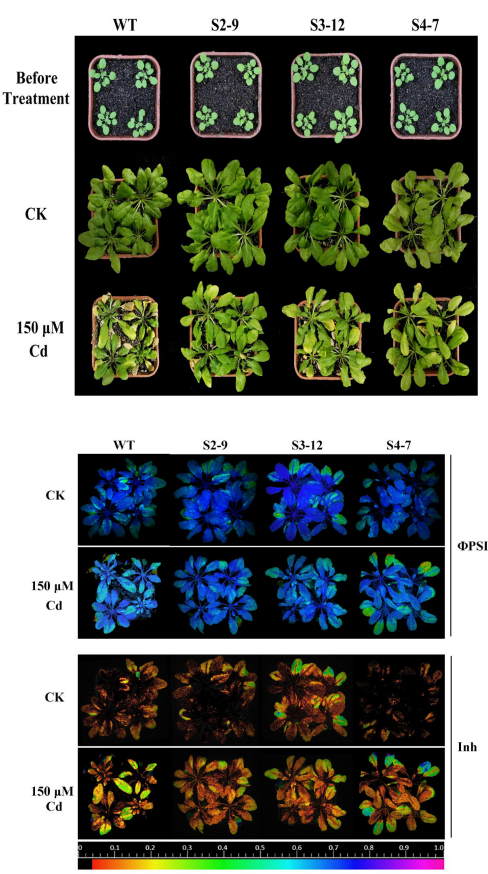

(b)

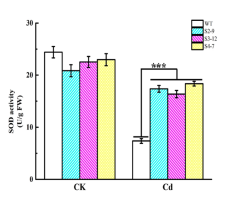

(d)

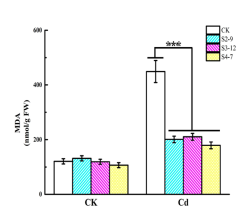

(g)

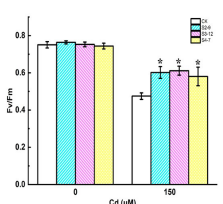

(i)

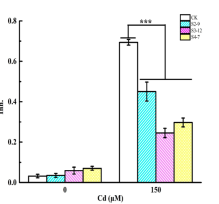

(c)

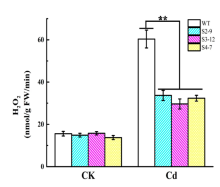

(e)

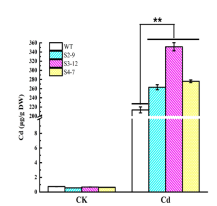

(h)

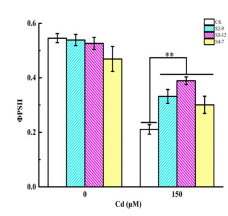

(j)

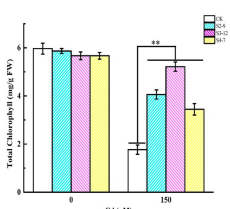


(a)

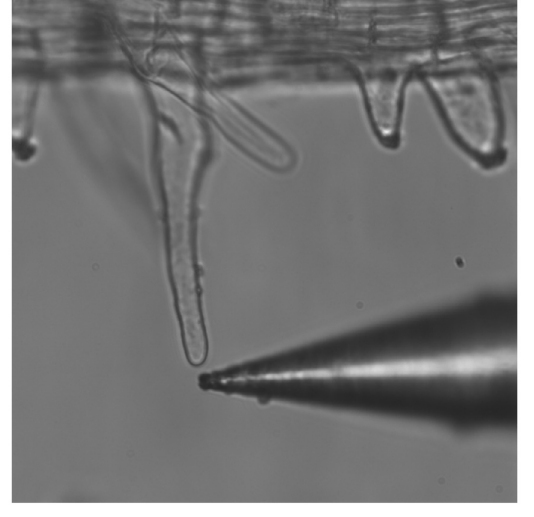

(c)

WT
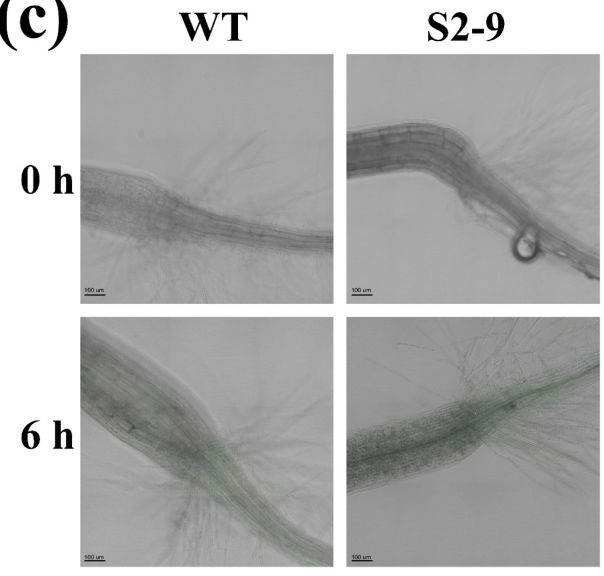

$12 \mathrm{~h}$
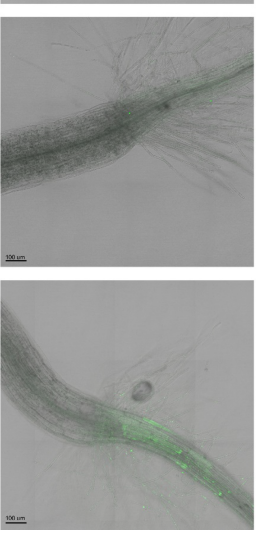

(b)

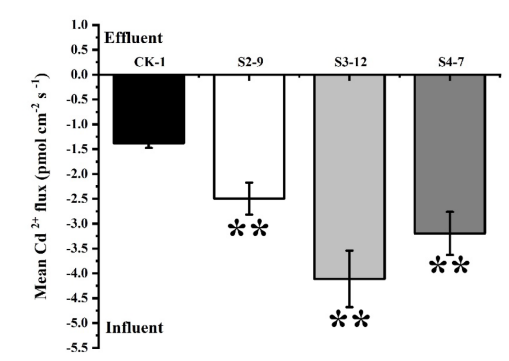

S3-12
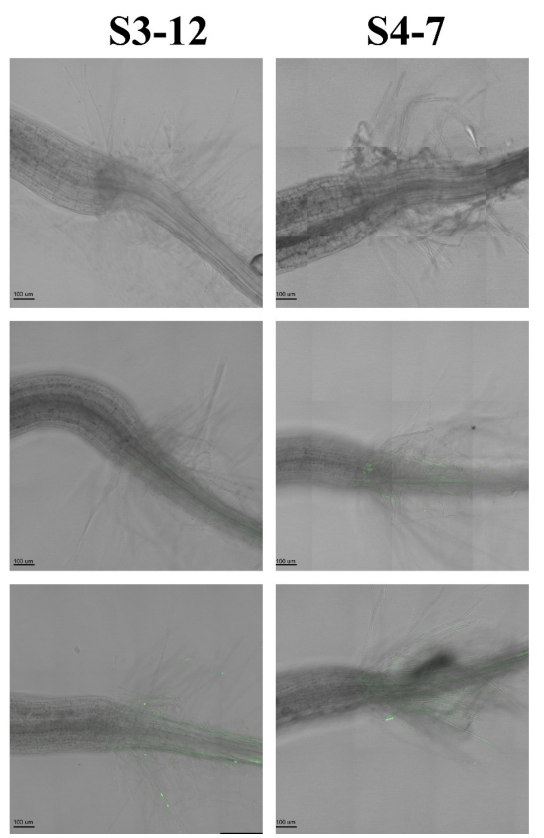
(a)

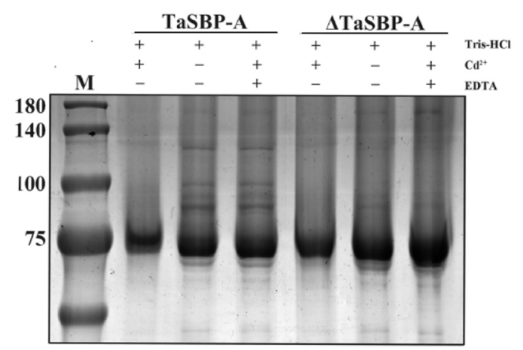

(c)

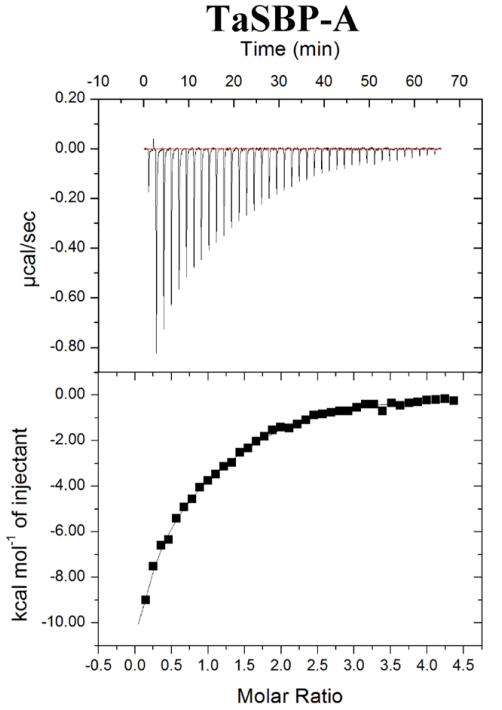

(d)

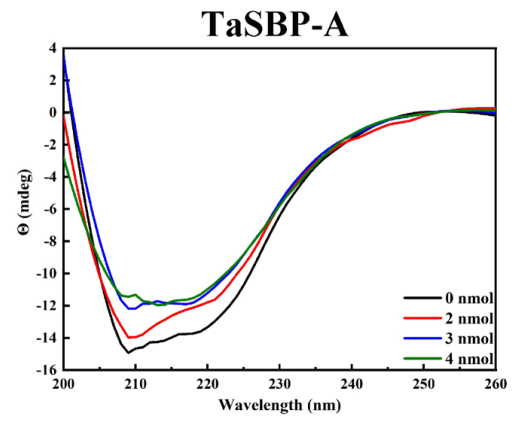

(b)

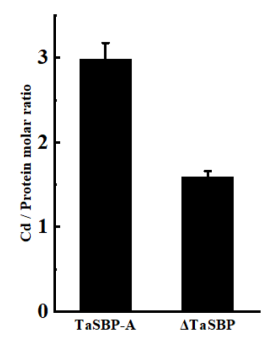

$\Delta$ TaSBP-A

Time (min)

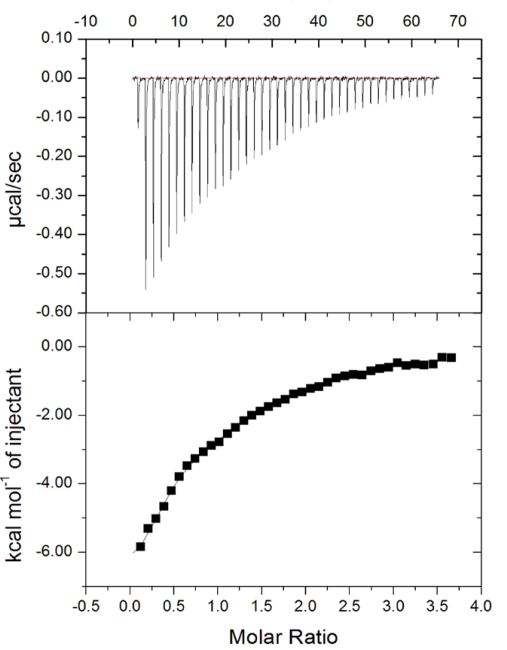

$\Delta$ TaSBP-A

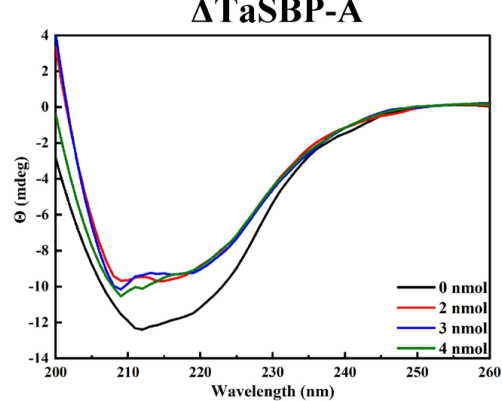




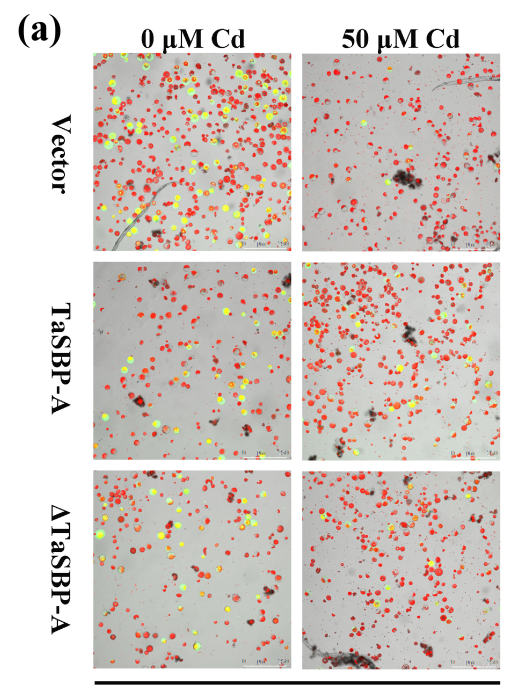

(b)

$12 \mathrm{~h}$
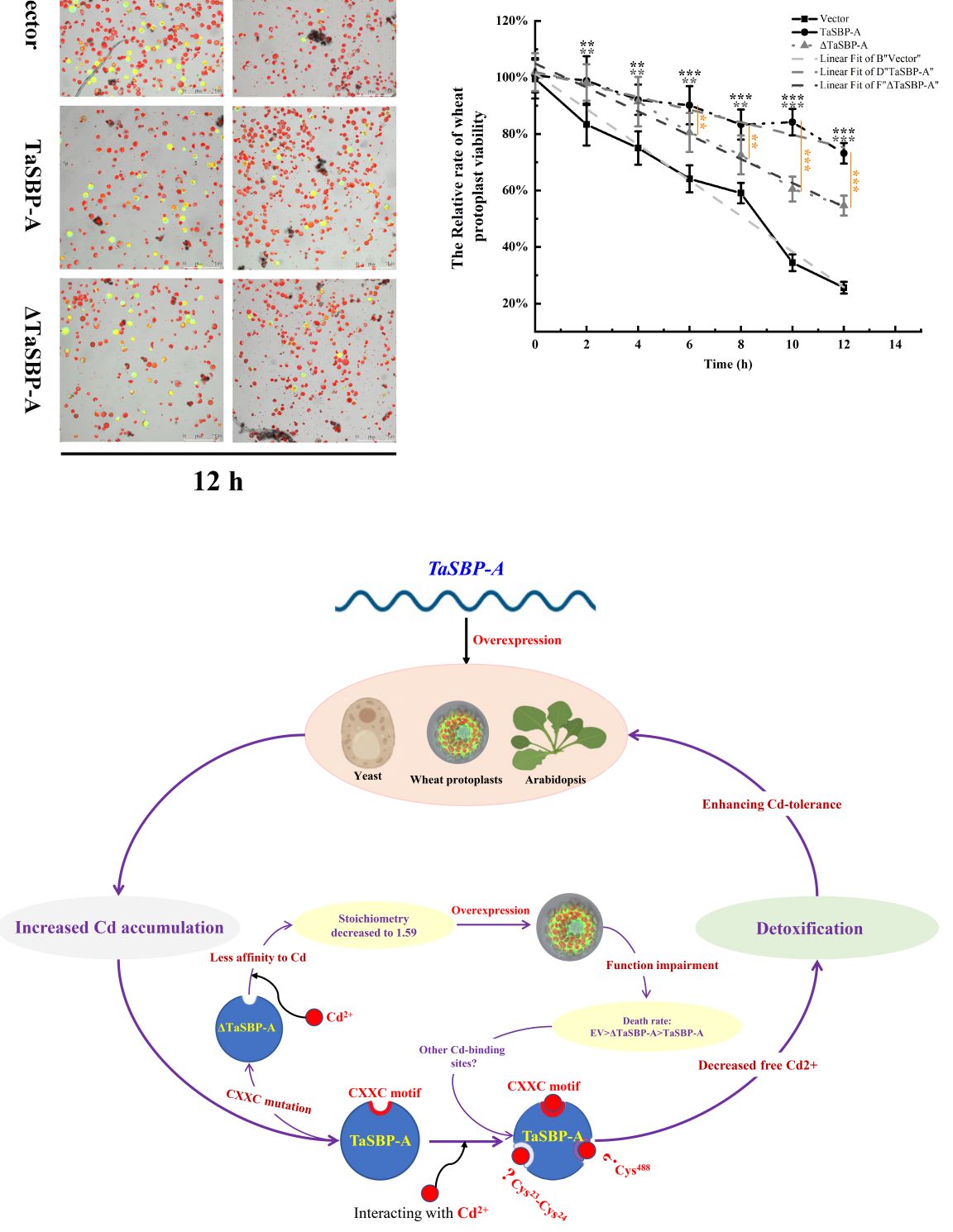

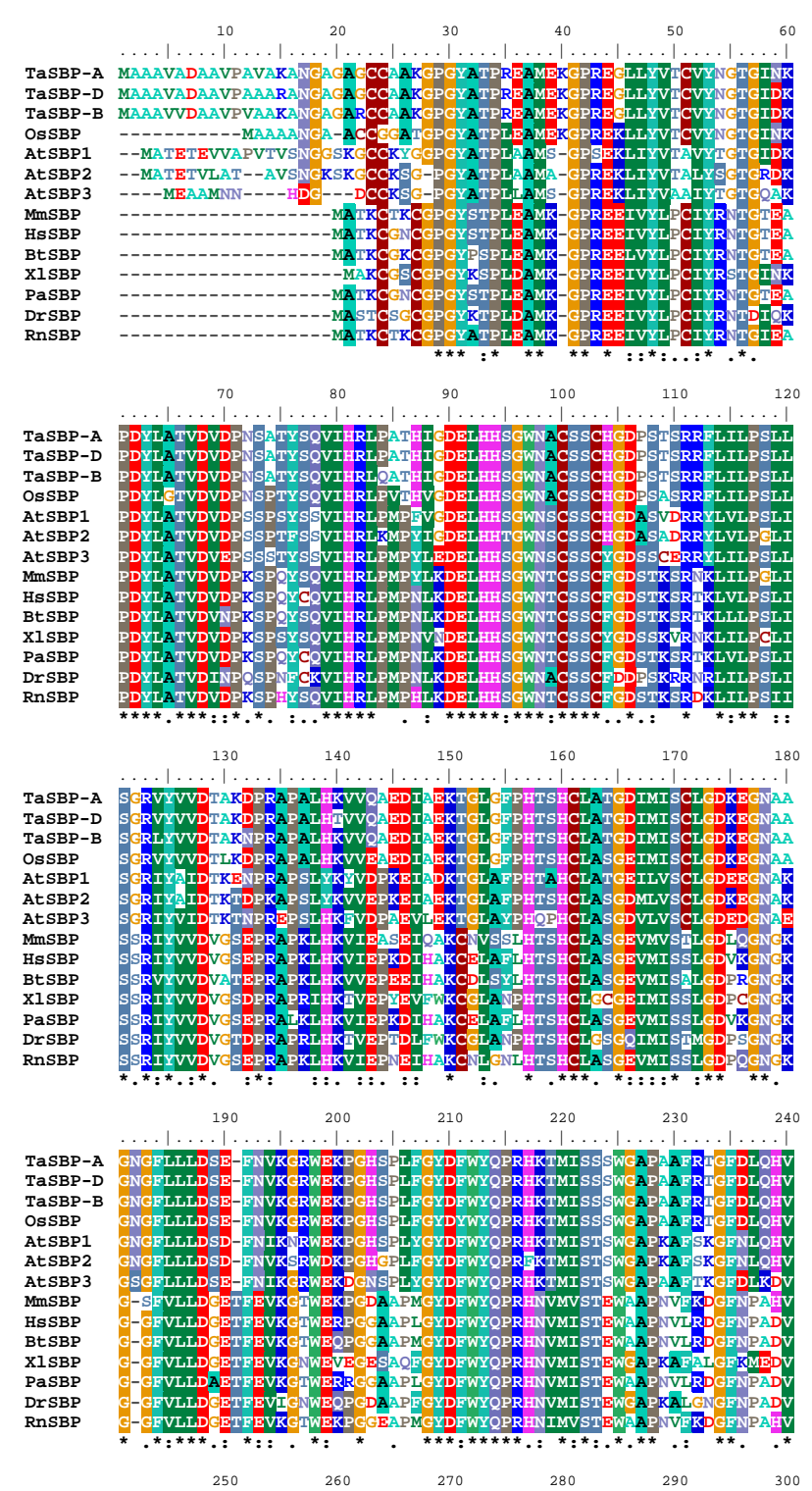

(a)

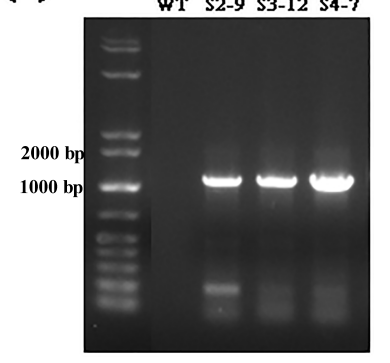

(b)

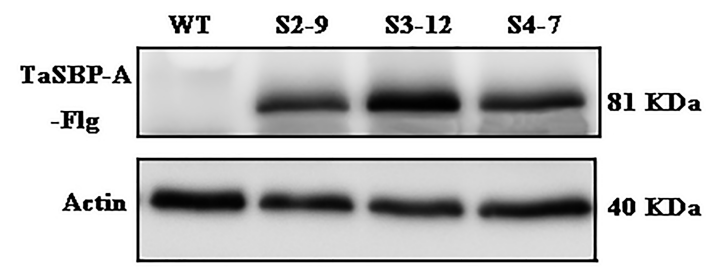


(a)
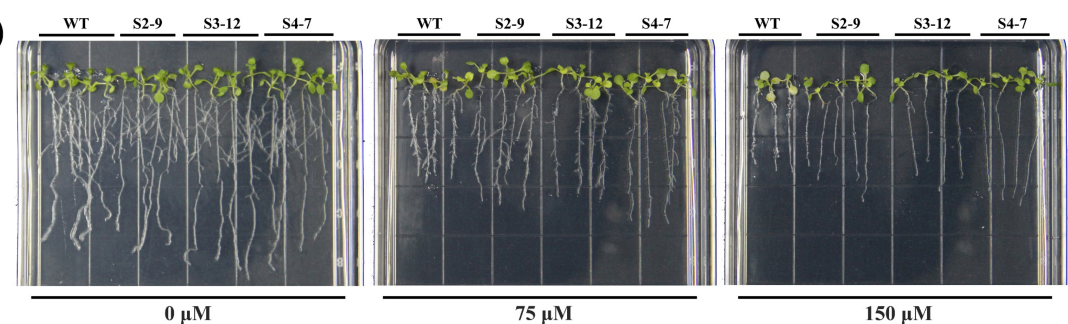

(b)

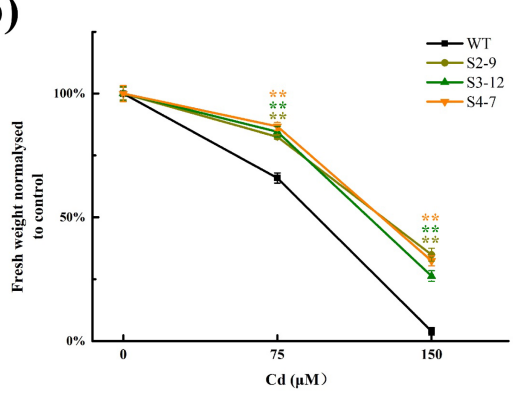

(d)

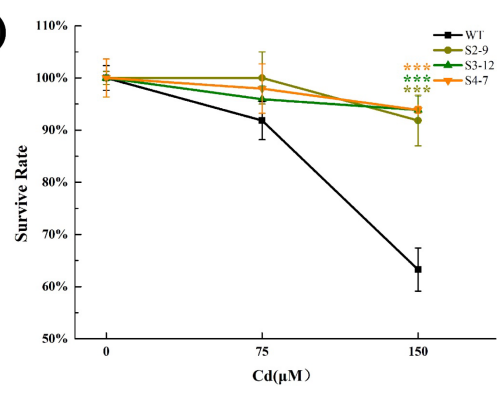

(c)

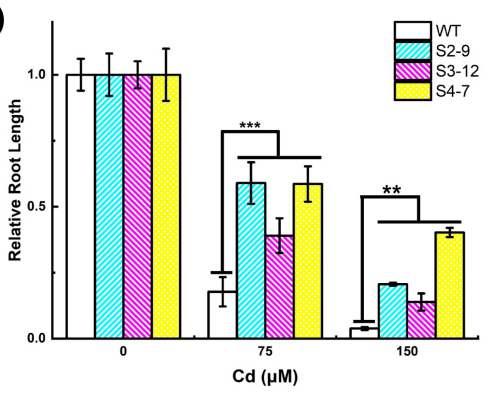

(e)

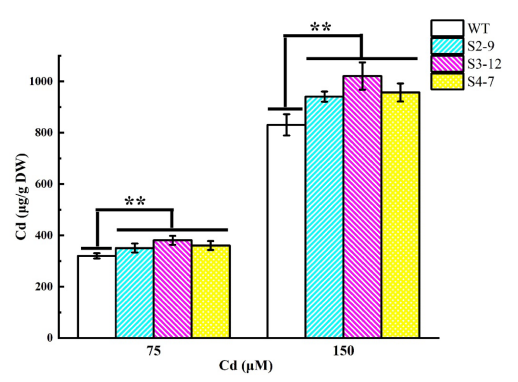

(a)

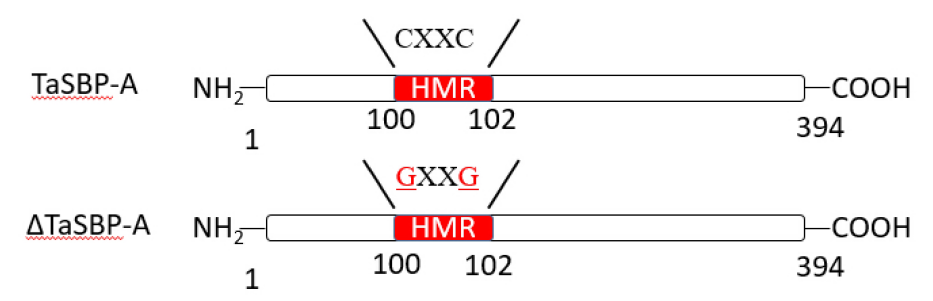

(b)
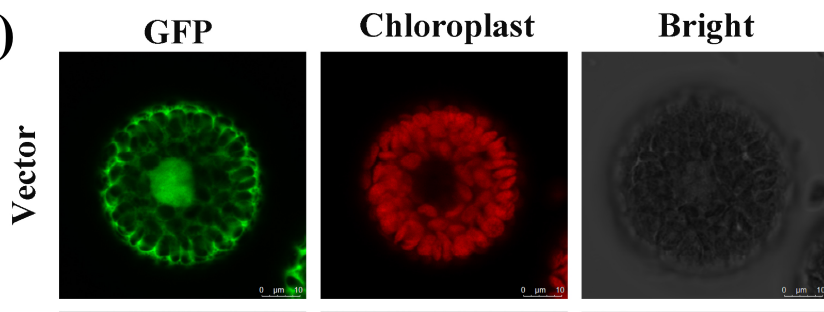

Merged
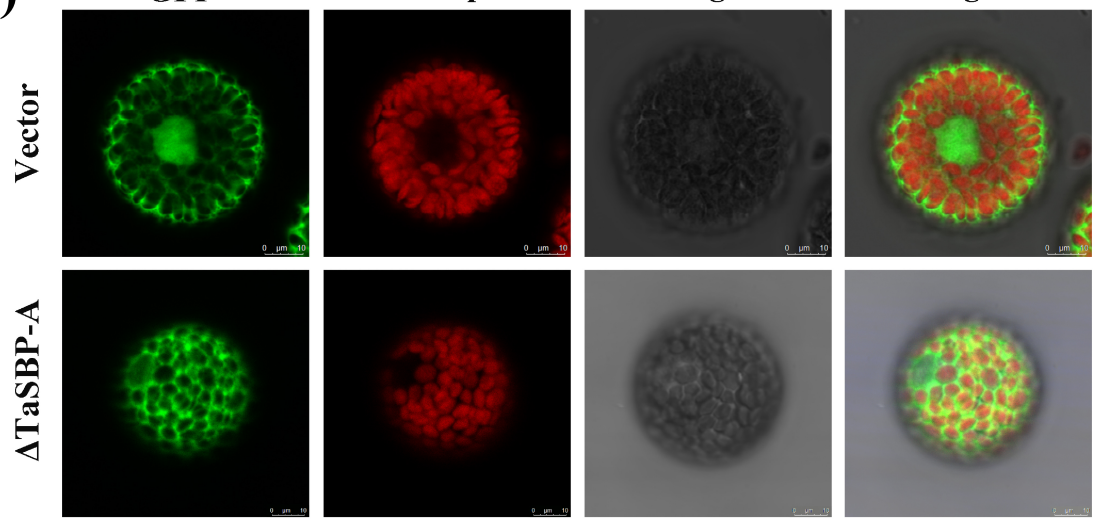


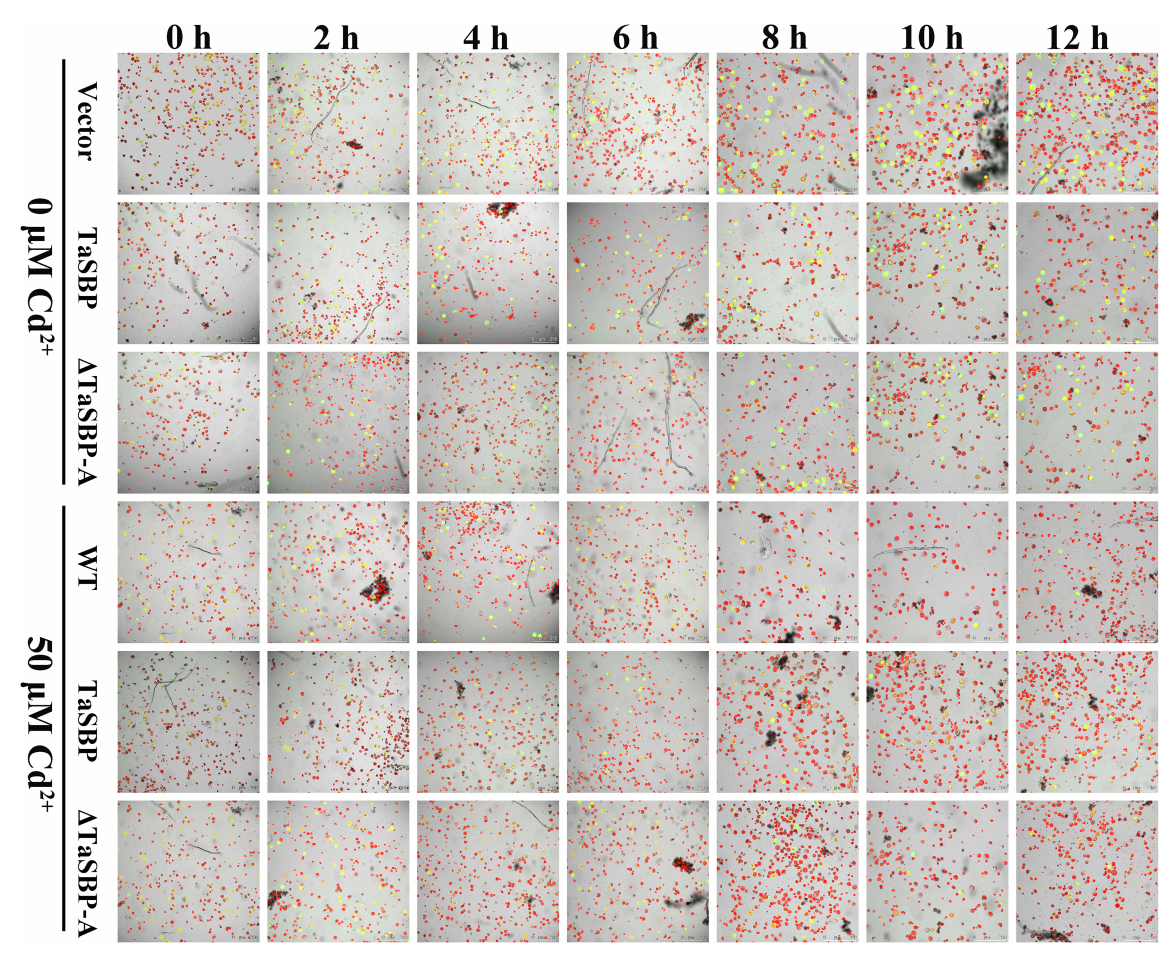



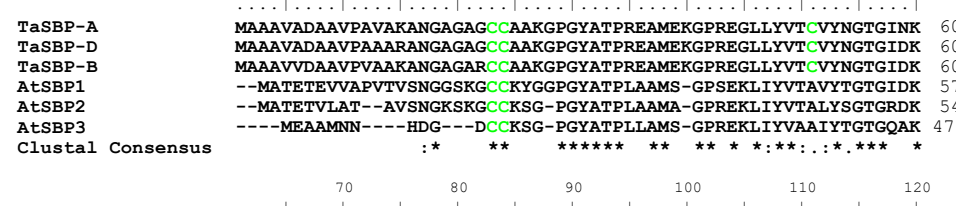

TASBP-A PDYLATVDVDPNSATYSQVIHRLPATHIGDELHHSGWNACSSCHGDPSTSRRFLILPSLI PDYLATVDVDPNSATYSQVIHRLPATHIGDELHHSGWNACSSCHGDPSTSRRFLILPSLL 120 TaSBP-B PDYLATVDVDPNSATYSQVIHRLQATHIGDELHHSGWNACSSCHGDPSTSRRFLILPSLI 120 AtsBe PDYLATVDVDPSSPSYSSVIHRLPMPFVGDELHHSGWNSCSSCHGDASVDRRYLVLPSLI 117 PDYLATVDVDPSSPTESSVIHRLKMPYIGDELHHTGWNSCSCHGDASADRRYLVLPGLI 11

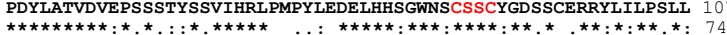

Clustal Consensus

$$
130
$$$$
140
$$

TASBP-A

TaSBP-D

AtSBP1

AtSBP2

SGRVYVVDTAKD PRAPALHKVVQAEDIAEKTGLGFPHT SHCLATGDIMIS CLGDKEGNAA 180 SGRVYVVDTAKDPRAPALHTVVOAEDIAEKTGLGFPHTSHCLATGDIMIS CLGDKEGNAA 180 SGRIYAIDIKENPRAPSLYKYVDPKEIADKTGLAFPH SGRIYAIDTKTDPKAPSLYKVVEPKEIAEKTGLAFPHTSHCLASGDMLVSCLGDKEGNAK 17

AtsBP3

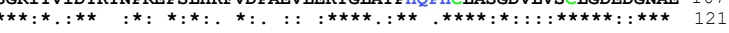

TASBP-A

200

210

220

240

TASBP-D

TaSBP-B

AtSBP2

AtSBP3

GNGFLLLDSEFNVKGRWEKPGHSPLFGYDFWYQPRHKTMISSSWGAPAAFRTGFDLQHVQ 240 GNGELIDSE GNGFLLLDSEFWKGRWERPGHSPLF 240 GNGFL IIDSDNIKNRWERPGHSPIYGYDFWYPRHKTMISTSWGAPKAFSKGFNLOHVA 237 GNGEL

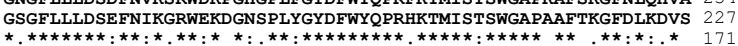

Clustal Consensus

$$
250260 \quad 270 \quad 280 \quad 290 \quad 300
$$

TASBP-A DGLYGRHLHVYDWPGGELKOTLDLGSTGLLPLEVRFLHDPSKDTGYVGCALTSNMVRFFK 300 DGLYGRHLHVYDWPGGELKQTLDLGSTGLLPLEVRFLHDPSKDTGYVGCALTSNMVRFFK 300 TaSBP-B $\quad$ DGLYGRHLHVYDWPGGELKQTLDLGSTGLLPLEVRFLHDPSKDTGYVGCALTSNMVRFFK 300 AtSBP1 DGLYGSHLHVYSWPGGEIKQLIDLGPTGLLPLEIRFLHDPSKDTGFVGSALSSNMIRFFK 297

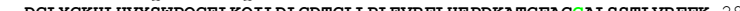

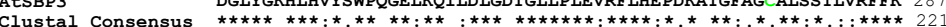

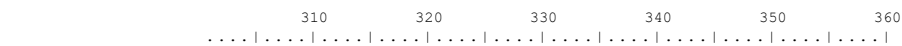
TADGSWSHEVAISIEPLKVRNWMLPEMPGLITDFVISLDDRYLYLVNWLHGDIROYNIED 360 TaSBP-

AtSBP1

AtSBP2

AtSBP3

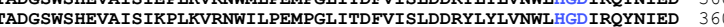
NSDETWSHEVVISVKPLKVENWILPEMPELITDFLISLDDRFIYFVNWLHGDIRQYNIED 35 NDDETWSHEVAISVEPLKVENWILPEMPGLITDFLISLDDRFLYCSNWLHGDIRQYNIED 347

Clustal Consensus

$$
370
$$$$
380
$$

TaSBP-A

TaSBP-D

AtSBP1

AtSBP2

PAKPVLAGQVVVGGLLQKGSDVVYVTDDDKEEQYAVPQVKGHRLRGGPQMIQLSLDGKRV 420 PAKPVLAGQVFVGGLLKGSDVVYVTDDDKEEQYAVPQVKGNRLRGGPQMIQLSLDGKRV 420 PKNPVLTGOIWVGGLLOKGSPVKAVGEDGNTFOFEVPOIKGKSLRGGPOMIOLSIDGKRL 417 AtSBP3

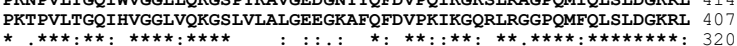

